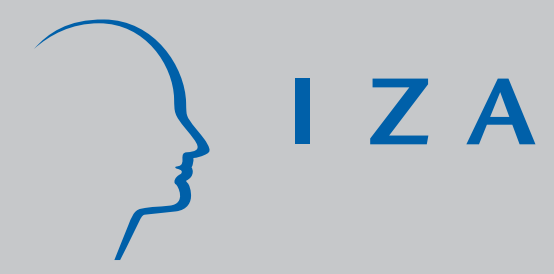

IZADP No. 1628

Can Endogenous Group Formation Prevent Coordination Failure? A Theoretical and Experimental Investigation

Philippe Raab

J une 2005 


\title{
Can Endogenous Group Formation Prevent Coordination Failure? A Theoretical and Experimental Investigation
}

\author{
Philippe Raab \\ Bonn Graduate School of Economics \\ and IZA Bonn
}

Discussion Paper No. 1628

June 2005

\author{
IZA \\ P.O. Box 7240 \\ 53072 Bonn \\ Germany \\ Phone: $+49-228-3894-0$ \\ Fax: +49-228-3894-180 \\ Email: iza@iza.org
}

\begin{abstract}
Any opinions expressed here are those of the author(s) and not those of the institute. Research disseminated by IZA may include views on policy, but the institute itself takes no institutional policy positions.

The Institute for the Study of Labor (IZA) in Bonn is a local and virtual international research center and a place of communication between science, politics and business. IZA is an independent nonprofit company supported by Deutsche Post World Net. The center is associated with the University of Bonn and offers a stimulating research environment through its research networks, research support, and visitors and doctoral programs. IZA engages in (i) original and internationally competitive research in all fields of labor economics, (ii) development of policy concepts, and (iii) dissemination of research results and concepts to the interested public.
\end{abstract}

IZA Discussion Papers often represent preliminary work and are circulated to encourage discussion. Citation of such a paper should account for its provisional character. A revised version may be available directly from the author. 


\section{ABSTRACT \\ Can Endogenous Group Formation Prevent Coordination Failure? A Theoretical and Experimental Investigation*}

This paper studies the effect of endogenous group formation on the outcome in two types of coordination games with multiple Pareto-ranked equilibria. Endogenous group formation means that in each period players are free to choose among two or more groups within which they want to play the coordination game. In the theoretical part we show that a simple myopic best reply dynamics under endogenous group formation leads to the payoff dominant outcome in both types of coordination games, independently of the initial strategy profile. In the experimental part we test this prediction. Our results show that the accuracy of the theoretical prediction is sensitive to the out-of-equilibrium properties of the respective coordination game. If the collective outcome is very sensitive to unilateral deviations, the coordination failure takes the same form under endogenous group formation as in the case of fixed groups. If, however, the coordination game is sufficiently robust against these unilateral deviations, coordination on the payoff dominant equilibrium is observed for the large majority of subjects under endogenous group formation. Moreover, in the former case we find the emergence of equally sized groups, while in the latter case large groups emerge. Interestingly, the respective group sizes can be interpreted as minimizing the individual's risk of encountering coordination deteriorating players.

JEL Classification: C72, C91, C92

Keywords: coordination games, endogenous group formation, minimum effort game, median effort game, experiment

Corresponding author:

Philippe Raab

BGSE and IZA

P.O. Box 7240

53072 Bonn

Germany

Email: philipperaab@yahoo.de

\footnotetext{
${ }^{*}$ Financial support by the Bonn Graduate School of Economics and the DFG is gratefully acknowledged. I thank Jörg Oechssler, Armin Falk, Antonio Cabrales, Reinhard Selten, Simon Gächter, Michael Evers, Philipp Kircher, Felix Marklein, Albrecht Morgenstern, and Burkhard Schipper for helpful discussions.
} 


\section{Introduction}

Coordination problems can be encountered quite frequently in economics. Conventions, emergence of technical standards, speculative attacks, team work are examples for such problems. In economics, we typically model coordination problems as symmetric noncooperative games with multiple strict Nash equilibria. Usually, equilibrium refinements cannot discriminate between the different equilibria. This raises the issue of strategic uncertainty which lays at heart of the coordination problem. Several outcomes are justifiable under rational reasoning. The question is how this uncertainty affects actual play.

VanHuyck, Battalio, and Beil (1990),(1991) (in the following VBB (1990) and (1991)) investigate two types of coordination games with Pareto-ranked equilibria in an experiment, namely the minimum and median effort game. Surprisingly, substantial coordination failure was observed: not the Pareto-dominant, but a Pareto-inferior outcome resulted in these games ${ }^{1}$.

Our paper introduces endogenous group formation to the above coordination games. Endogenous group formation means that players are free to choose in each period between two or more groups where they want to play the coordination game. This additional choice variable can be encountered in many real world situations displaying the main feature of a coordination problem. In the example of speculative attacks agents may choose between different currencies to attack, team players may have the possibility to choose between different teams to engage in, etc.. Endogenous group formation is interesting to study in the context of coordination games because it may be the force that drives coordination to the payoff dominant equilibrium. In fact, we show that already with two eligible groups a myopic best reply process yields the payoff dominant outcome in both types of games, independently of the initial distribution of actions.

Two forces drive the result: First, endogenous group formation generates an evolutionary pressure between groups and thereby endogenizes group sizes. That is, players can always switch to the "better" group, thereby creating large and small groups. Second, the smaller the groups are, the easier is coordination on more efficient outcomes. The latter point assumes that the difficulty to coordinate increases with the group size and vice versa. For the most extreme case that a group consists of a single player only, this argument becomes straightforward in the above coordination games (this holds because the summary statistics of the single player group is equal to the player's effort). The theoretical result of payoff dominance under endogenous group formation is in contrast to the results of the same kind of analysis with fixed groups. While the myopic best reply dynamics yields the Pareto-worst equilibrium in the minimum effort game, all equilibria are equally likely in the median effort game with fixed groups.

The experimental part of the paper tests the prediction of payoff dominance under endogenous group formation for both the median and the minimum effort game. For this purpose, we reproduced as closely as possible the environments of past experiments on the median and minimum effort game with fixed groups. In particular, we fixed the first period group sizes in the endogenous group formation treatments to numbers which were known to produce coordination failure. In each subsequent period, subjects had to choose between two groups, in addition to their effort decision. We provided players with all information necessary for the

\footnotetext{
${ }^{1}$ The median and the minimum effort game share the following characteristics: Every player chooses an effort. The efforts determine the value of the summary statistics (the minimum or the median). The payoff function induces the following properties: First, a player's best reply consists of choosing an effort equal to the expected value of the summary statistics. Consequently, an equilibrium consists in all players choosing the same effort. Secondly, equilibria at higher effort levels strictly Pareto-dominate those at lower levels.
} 
myopic best reply process to lead to the payoff dominant solution. Players received in each period the history of group sizes and summary statistics in the two groups.

Our experimental results show that the sensitivity of the underlying coordination game to deviations from a current equilibrium (out-of-equilibrium property) is crucial for endogenous group formation being successful in improving coordination results. For the minimum effort game the coordination outcomes under endogenous group formation very much resemble the results with fixed groups, i.e. we observe coordination on the Pareto-worst outcome. This holds because unilateral downward deviations from the current minimum are effective in driving coordination outcomes downwards. The additional choice possibility to select one of two groups cannot overcome this problem. In contrast, the median effort game is robust against such mutations most of the time. Pareto-improving group changes may therefore occur. In fact, in contrast to the median effort game with fixed groups, we observe that under endogenous group formation the overwhelming majority of subjects end up in a group with the maximum median. Moreover, we observe the emergence of large/small groups in the median effort game under endogenous group formation. While equally sized groups result in the minimum effort game.

The next section briefly reviews the related literature. The third section presents the model and works out the theoretical prediction. The fourth section explains the experimental design. The fifth section states the results. The sixth section discusses them, and the seventh section concludes.

\section{Related Literature}

Oechssler (1997),(1999) first showed that for 2-player coordination games a myopic best reply process under endogenous group formation leads to the efficient equilibrium under some fairly general initial conditions concerning the distribution of actions in the population. Ely (2002) gets the same result but independently of the initial conditions. We apply the idea of endogenous group formation to the minimum and median effort game using the method of stochastic stability analysis (see Kandori, Mailath, and Rob (1993), Young (1993), Nöldeke and Samuelson (1993),(1997). In the studies mentioned before, players always play a 2-player coordination game. Endogenous group formation only alters the set of players with whom a player is matched to play the respective game. In contrast, in our work endogenous group formation varies the number of players who actually play the game.

VBB $(1990,1991)$ initiated a wave of experimental literature which can be divided into two categories. The interest of the first branch of literature was to check how vulnerable the result of coordination failure was to changes in the treatment variables of VBB's original setting. For the minimum effort game VBB (1990) themselves alter the number of players. They find that with two players coordination results reach the payoff dominant equilibrium. Berninghaus and Ehrhart (1998) increase the number of repetitions of the static game. Berninghaus and Ehrhart (2001) alter the informational environment. For the median effort game VanHuyck, Battalio, and Rankin (2001) implement a finer grid size for the possible effort levels.

The second branch of literature introduced new market institutions to the original design of VBB's $(1990,1991)$ experiments. Most of these studies aim to show that these institutions can help to overcome the coordination failure. For the minimum effort game Bornstein, Gneezy, and Nagel (2002) implement a Bertrand-like competition between groups in the lab. Each of two groups played the minimum effort game. However, only the group with the higher 
minimum was rewarded. The group with the lower minimum got nothing. In fact this strong competitive pressure increases coordination substantially towards efficiency. Cooper, Jong, Forsythe, and Ross (1992) introduce monetary outside options and communication ("cheap talk") to the minimum effort game. Blume and Ortmann (2000) apply pre-play communication to the median effort game. Keser, Ehrhart, and Berninghaus (1998) introduce a local interaction environment to an analogous type of the three person minimum effort game. They find that interaction on a circle causes coordination on the Pareto-inferior solution. Cachon and Camerer (1996) either force subjects to pay a fee to participate in the minimum or median effort game, or give subjects the possibility to opt out without paying the fee. In the median effort game both treatments have an efficiency enhancing effect. However, in the minimum effort game only the latter treatment can substantially increase efficiency. Devetag (2001) shows that playing a coordination game with a payoff dominant outcome first, enhances efficiency in the minimum effort game. VanHuyck, Battalio, and Beil (1993) auction off the right to participate in the median effort game.

To our knowledge, there are very few experiments on endogenous group formation. Ehrhart and Keser (1999) conduct a public good game with 9 subjects. In each period subjects can either stick to their old group, make a costly switch to another group or incur a cost for setting up a new group. They observe a lot of group switches. In particular, it seems that cooperators are running away from defectors while defectors chase cooperators.

This paper adds to the second branch of the literature on the VBB $(1990,1991)$ coordination games by introducing endogenous group formation to these games.

\section{Model and Theoretical Predictions}

We have $i \in\{1, \ldots, N\}=I$ players participating in the game. A pure strategy of a player in the static game consists of choosing one out of two groups $X$ and $Y$ and his effort decision in the group chosen. Let $g_{i} \in\{X, Y\}=G$ be the group decision of player $i$ and $e_{i} \in\{\underline{e}, \ldots, \bar{e}\}=E$ the effort decision of player $i$ in his chosen group $g_{i} \in\{X, Y\}$. A pure strategy is denoted by $s_{i}=\left(g_{i}, e_{i}\right) \in G \times E$. Let $n_{g}$ be the number of players playing in group $g, g \in\{X, Y\}$. Finally let $e_{i_{g}}$ denote the effort of player $i$ in group $g$.

The payoff of player $i$ who decides to interact in group $g$ is determined in the following way:

$$
\pi_{i}\left(e_{i_{g}}, e_{-i_{g}}\right)=a M_{g}-b\left(e_{i_{g}}-M_{g}\right)^{\delta}+c
$$

where $e_{-i_{g}}$ is the vector of efforts of all other players who decided to interact in the same group $g$ as player $i$ and $a, b, c$ are some positive real valued numbers. $M_{g}$ is a summary statistics of the effort levels $e_{i_{g}}$ of all players in group $g$. That is, $M_{g}=f\left(e_{i_{g}}, e_{-i_{g}}\right)$ with $f:\left(e_{i_{g}}, e_{-i_{g}}\right) \rightarrow\{\underline{e}, \ldots, \bar{e}\}=E$. For equation (1) to yield the payoff function of the median effort game we set $\delta=2$ and $M_{g}$ equal to the median of the group efforts ${ }^{2}$. In order to yield the minimum effort game we set $\delta=1$ and $M_{g}$ equal to the minimum of all efforts in group $g$. Note that both statistics share the following property: If a group consists of a single subject, then the value of the summary statistics is equal to this player's effort. By nature of the payoff function (1) such a single player would choose the maximal effort $\bar{e}$ reaching the maximal

\footnotetext{
${ }^{2}$ Note that if a group has an even number of players the two "middle" numbers fulfill the definition of the median. If these two numbers are different we assume for the theoretical part that the lower one determines the median of the group.
} 
payoff. Beside the endogenous group formation possibility this property turns out to be the driving force behind the result of the dynamics presented below.

Before going to the dynamics we state the set of Nash equilibria in the static game presented so far:

Proposition 1 In any Nash equilibrium all players choose the same effort level. Moreover, if $\exists g$ with $n_{g} \leq 1$ then $e_{i}^{*}=\bar{e}, \forall i \in I$.

It is easy to see that Proposition 1 holds. By nature of $M_{g}$ (which is either the minimum or the median) equation (1) implies that the best reply of a player with respect to his effort decision is to play the value of the summary statistics $M_{g}$ of the given group as long as the group size is not smaller than 2. Moreover, as long as the summary statistics are not equal in both groups, a profitable deviation towards the group with the higher summary statistics exists.

Now look at the case where a group consists of at most one player. As mentioned above, the value of the summary statistics in a one player group is equal to the player's effort. Profit equation (1) therefore implies that a single player's best response is to choose the maximum effort level $\bar{e}$. All other players only remain in their group if they play the maximum effort, too. Otherwise they would have an incentive to switch to the group with the single player. If all players are in one group and no one is in the other group, then as long as not all players are choosing the maximum effort level, every player has an incentive to switch to the empty group with the maximum effort level for the same reason as above. Therefore the proposition holds.

All equilibria can be Pareto-ranked under endogenous group formation like in the original games of VBB $(1990,1991)$ with fixed groups, with all players playing $\bar{e}$ as effort being the payoff dominant equilibrium. Also the min-max strategies remain the same for both the median and minimum effort game.

In the following we will show that a myopic best reply process under endogenous group formation ends up in the efficient outcome in the coordination game specified so far. The dynamics of the system is assumed to proceed in discrete time, indexed $t=1,2, \ldots$. A state $\omega^{t}$ at date $t$ is completely characterized by

$$
\omega^{t}=\left(s_{1}^{t}, \ldots, s_{N}^{t}\right) \in(G \times E)^{N}
$$

where $s_{i}^{t}=\left(g_{i}^{t}, e_{i}^{t}\right)$ is the group and effort decision of player $i$ in period $t$. Payoffs in the respective period are determined according to equation (1). Given this payoff function every player $i \in I$ is assumed to play his myopic best reply with respect to his group decision and effort decision $\left(\hat{s}_{i}^{t}=\left(\hat{g}_{i}^{t}, \hat{e}_{i}^{t}\right)\right)$ in period $t$. Like above we denote by $e_{i_{g}}$ the effort $e_{i}$ or player $i$ if he decided to play in group $g_{i} \in\{X, Y\} . \hat{s}_{i}^{t}$ is then determined by the following equation:

$$
\hat{s}_{i}^{t}=\operatorname{argmax}_{s_{i}} \quad \pi\left(e_{i_{g}}, M_{g}^{t-1}, n_{g}^{t-1}\right)=a M_{g}^{t-1}-b\left(e_{i_{g}}-M_{g}^{t-1}\right)^{\delta}+c
$$

where $M_{g}^{t-1}$ is the value of the summary statistics of group $g$ in period $t-1$, and $n_{g}^{t-1}$ is the number of players of group $g$ in period $t-1$. That is, given the values of the summary statistics of the two groups in the preceding period and the number of subjects in the two groups in the preceding period, player $i$ chooses his group and effort such that his payoff according to equation 11 is maximized. Note that the group size $n_{g}^{t-1}$ enters through the 
summary statistics $M_{g}^{t-1}$ in equation (3). In particular, we assume that only when one of the groups is sufficiently small in the preceding period (one or zero players) the player might expect the summary statistics in the next period to be equal to his own effort. By the nature of the payoff function he therefore chooses the maximum effort in that case. In all other cases his myopic view makes him believe that the next period's values of the summary statistics in both groups will equal the ones of the preceding period. We make the following assumption:

\section{Assumption 1 (Group Size)}

(i) If $n_{g^{\prime}}^{t-1}=1$ and $g_{i}^{t-1}=g^{\prime}$ then $\hat{g}_{i}^{t}=g^{\prime}$ and $\hat{e}_{i_{g^{\prime}}}^{t}=\bar{e}$.

(ii) If $n_{g^{\prime}}^{t-1}=0$ then $\hat{g}_{i}^{t}=g^{\prime}$ and $\hat{e}_{i_{g^{\prime}}}^{t}=\bar{e}$.

(iii) For all other cases the player takes the summary statistics in the respective groups as given.

We make the following assumption for the case that a player is indifferent between the two groups given that he chooses his payoff maximizing effort in each group:

Assumption 2 (Indifference) If the optimal effort decisions in both groups $g \in\{X, Y\}$ given the values of $M_{g}^{t-1}$ and $n_{g}^{t-1}$ yield the same payoff according to equation (1) then the player chooses one of the two groups, each with strictly positive probability.

The assumptions 1 and 2 imply the following myopic best reply behavior: As long as a player $i$ is not a single player in group $g^{\prime} \in\{X, Y\}$ in period $t-1$ and the other group $g^{\prime \prime} \neq g^{\prime} \in\{X, Y\}$ is not empty, player $i$ chooses the group with the higher value of the summary statistics $M_{g}^{t-1}(g \in\{X, Y\})$ in period $t-1$ with his effort equal to that value. Moreover, assumption 2 tells us that if both values of the summary statistics are the same $\left(M_{X}^{t-1}=M_{Y}^{t-1}\right)$, player $i$ chooses any of the two groups (each with a strictly positive probability) and plays an effort equal to the value of the summary statistics. If, however, player $i$ is a single player in group $g$ in period $t-1\left(n_{g}^{t-1}=1\right)$, then he sticks to his group of period $t-1$ and chooses the maximum effort $\bar{e}$. This holds because the single player's effort is equal to the value of the summary statistics. This also drives behavior in the next case. If in period $t-1$ group $g^{\prime} \in\{X, Y\}$ is empty and the summary statistics of the group $g^{\prime \prime} \neq g^{\prime} \in\{X, Y\}$ containing all players is lower than the maximum value, all the players switch to group $g^{\prime}$ in period $t$ with the maximum effort $\bar{e}$.

It is easy to see that the myopic best reply decision dynamics induces a finite stationary vector Markov process ${ }^{3}$.

Let $P$ be the stationary Markov operator which is a transition matrix $P:(E \times G)^{N} \rightarrow$ $\Delta\left((G \times E)^{N}\right)^{4}$.

The dynamic model will be closed by the following assumption:

\footnotetext{
${ }^{3} \mathrm{It}$ is a vector process because each state is a vector in $(G \times E)^{N}$. It is finite because $(G \times E)^{N}$ is finite. It is a Markov process because the Markov property is fulfilled, i.e. $\operatorname{prob}\left(\omega^{t} \mid \omega^{t-1}, \omega^{t-2}, \ldots\right)=\operatorname{prob}\left(\omega^{t} \mid \omega^{t-1}\right)$. Finally, the process is stationary because players in each period follow their myopic best reply given through equation (3). That is $\operatorname{prob}\left(\omega^{t} \mid \omega^{t-1}\right)=\operatorname{prob}\left(\omega^{t+k} \mid \omega^{t+k-1}\right), k \in \mathbb{N}$.

${ }^{4}$ This matrix assigns to any state $\omega^{\prime} \in(G \times E)^{N}$ in some period $t$ the probabilities of being in any other possible state of $\omega^{\prime \prime} \in(G \times E)^{N}$ in period $t+1$. It is thus an arrangement of transition probabilities $p_{\omega^{\prime} \omega^{\prime \prime}}$ in a $\left(2^{N} \cdot \sharp\left(E^{N}\right)\right) \times\left(2^{N} \cdot \sharp\left(E^{N}\right)\right)$ matrix $\left(P=\left(p_{\omega^{\prime} \omega^{\prime \prime}}\right)_{\omega^{\prime}, \omega^{\prime \prime} \in(G \times E)^{N}}\right.$, where $p_{\omega^{\prime} \omega^{\prime \prime}}:=\operatorname{prob}\left(\omega^{\prime}=\omega^{t+1} \mid \omega^{\prime \prime}=\right.$ $\left.\omega^{t}\right), \quad p_{\omega^{\prime} \omega^{\prime \prime}} \geq 0 \forall \omega^{\prime}, \omega^{\prime \prime} \in(G \times E)^{N}$ and $\left.\sum_{\omega^{\prime \prime} \in(G \times E)^{N}} p_{\omega^{\prime} \omega^{\prime \prime}}=1\right)$.
} 
Assumption 3 (Noise) With some probability $\varepsilon \in(0, a]$, where a is sufficiently small, every player $i$ randomizes with full support on $(G \times E)$ instead of following his myopic best reply determined by equation (3).

Assumption 3 induces a perturbed Markov operator $P(\varepsilon)$. We call a player not following his myopic best reply mutating. Let $\varphi$ be a vector which assigns to any possible state $\omega \in$ $(G \times E)^{N}$ the probability of being in that state $\omega . \varphi$ is called an invariant distribution $\varphi$ of the unperturbed Markov chain if $\varphi=\varphi P$. Consequently the invariant distribution of the perturbed Markov chain $\varphi(\varepsilon)$ is defined by $\varphi(\varepsilon)=\varphi(\varepsilon) P(\varepsilon)$. Define the limiting invariant distribution by $\varphi^{\diamond}:=\lim _{\varepsilon \rightarrow 0} \varphi(\varepsilon)$ and $\varphi^{\diamond} P=\varphi^{\diamond}$. The following analysis focuses on the unique limiting invariant distribution $\varphi^{\diamond}$ of $P$. In particular the focus is on how to characterize this probability vector since it provides a description of the long run outcome when the noise goes to zero. The following proposition shows that only states which are Pareto efficient are in the support of the limiting invariant distribution. That is, in both the median and the minimum effort game, endogenous group formation induces a dynamic towards the payoff dominant equilibrium.

Proposition 2 Given previous assumptions and the myopic best reply process as induced by equation (3), then the support $A^{\diamond}$ of the unique limiting invariant distribution $\varphi^{\diamond}$ consists of all states $\omega^{\diamond}$ that are payoff dominant Nash equilibria. That is:

$$
A^{\diamond}=\left\{\omega^{\diamond} \mid g_{i} \in\{X, Y\} \text { and } e_{i}=\bar{e}, \forall i \in I\right\}
$$

The proof is consists of a series of steps and is transferred to appendix A.

The result is driven by two sources, namely the evolutionary pressure through endogenous group formation and the property of the summary statistics. Subjects can always switch to the "better" group. Thereby the group size of the "better" group increases while the group size of the "worse" group decreases. As the group size of the "worse" group becomes sufficiently small, the property of the summary statistics comes in. In particular, the summary statistics of a single player group is equal to the player's effort. Therefore, such a player will always choose the maximum effort. This in turn triggers migration to his group up to the point where everybody is in a group with the maximum value of the summary statistics. For the case that the values of the summary statistics are the same in both groups the indifference assumption 2 comes in. In particular, it warrants that a single player or empty group emerges with positive probability in such a case. As a above this ensures coordination on the payoff dominant outcome.

The same mutation counting argument applied to a myopic best reply dynamics with a fixed group generates the Pareto-worst Nash equilibrium in the minimum effort game, while any Nash equilibrium is possible in the median effort game. In the minimum effort game one player mutating to the lowest effort level is enough to lead the following unperturbed dynamics to the lowest effort Nash equilibrium from any other Nash equilibrium. On the other hand, starting from the lowest effort Nash equilibrium, all players must mutate to the same higher value in order to reach a Nash equilibrium with a higher value permanently. Permanently means that the unperturbed dynamics following the mutations does not lead out of the state. Therefore, a process in which mutation probabilities become smaller and smaller will lead to the Paretoworst equilibrium. In the median effort game we need always half of the players mutating on the same value to reach a Nash equilibrium different from the actual one. That is, all Nash equilibria have positive probability in the limit to describe the coordination outcome as the mutation probabilities go to zero. 
We derive from proposition 2 the following two hypotheses which we want to test in the experimental part:

Hypothesis 1 In contrast to a fixed groups setting, subjects coordinate on the payoff dominant solution under endogenous group formation, both in the minimum and median effort game.

Hypothesis 2 Players behave according to the myopic best reply as given by equation (3).

\section{Design}

Past experiments on the minimum and median effort games have shown that certain design features like the length of interaction, the number of subjects in the experiment, the information,...(see section 2) are critical for inducing coordination failure in the two games. Our aim is to reproduce the experimental environments as closely as possible in the endogenous group formation treatments that are known to produce coordination failure with fixed groups. We conducted three different treatments in this study. Two endogenous group formation treatments, one for the median effort game (in the following MedGT), and one for the minimum effort game (in the following MinGT). For the median effort game we also ran one control treatment with fixed groups (in the following MedCT). We generated 8 independent observations in both MedGT and MedCT. For MinGT we generated 6 independent observations. The experiment was run computer based with the experimental software z-tree (Fischbacher (1998)).

The group treatments are designed as follows. Like in the papers of VBB $(1990,1991)$ subjects interacted for 10 periods. For each period, except the first one, each subject had to make two decisions simultaneously: the group decision and the effort decision. The group decision consisted in choosing one out of two groups $\mathrm{X}$ and $\mathrm{Y}$. The effort decision consisted in choosing an effort $e_{i}^{t} \in\{1,2, \ldots, 7\}$. In the first period, however, subjects were equally distributed among the two groups at random and only had to take their effort decision. This was done in order to generate the same initial coordination failure which has been observed for the respective number of subjects in fixed groups in other studies. The effort levels of the group members determined the respective summary statistics for that group (in MedGT the median ${ }^{5}$, in MinGT the minimum). The summary statistics of one's group and the own effort in turn determined the payoff of a subject according to equation (1) (see section 3). Parameters $a, b, c$, and $\delta$ of equation (1) in MedGT are chosen like in Cachon and Camerer (1996) to be 20, 10, 120, 2. Parameters $a, b, c$, and $\delta$ in MinGT are chosen like in Bornstein, Gneezy, and Nagel (2002) to be $20,10,60,1$. The payoff tables generated by these parameters for the respective game are depicted in Table 1 (for the median effort game) and Table 2 (for the minimum effort game) in the appendix C. Both tables display payoffs in experimental currency $(\mathrm{ExCu})$. Note that the relation of the payoff parameters a, b, and c are exactly the same as in most of the studies on coordination games à la VBB $(1990,1991)$. With both parameter settings, substantial coordination failure was observed in fixed groups in the studies just mentioned.

As historical data subjects got the total history up to the current period of own group and effort decisions, number of subjects and respective summary statistics in the two groups, their

\footnotetext{
${ }^{5}$ Note that for an even number of group members both "middle" numbers satisfy the definition of the median. Like Cachon and Camerer (1996) we determined one of the two numbers with equal probability to be the median. The theoretical prediction for the myopic best reply dynamics under endogenous group formation remains the same, given the payoff function and all kind of risk attitudes.
} 
own period payoff, and finally the accumulated payoff. This information was given on the computer screen where subjects had to enter both their group and effort decisions.

18 subjects participated in each observation of the MedGT. Since in the first period subjects were equally distributed among the two groups $\mathrm{X}$ and $\mathrm{Y}, 9$ subjects were placed in each group in the first period. Note that this is the same number of subjects like in VBB (1991) where interaction takes place in fixed groups. In the minimum treatment 14 subjects participated in each observation of MinGT. That is in the first period 7 subjects were allocated to each group. This is the same number of subjects as in the fixed group control treatment of Bornstein, Gneezy, and Nagel (2002) (in the following BGN MinCT). A lower number of participants in the MinGT as compared to the MedGT was chosen for the following reason. As explained before the minimum effort game is sensitive to unilateral downwards deviations. In the MinGT we therefore expected dynamics to the payoff dominant equilibrium to take place if in the very first periods the usually observed downward trend of the minima would not take place too quickly. Only in that case subjects can switch to groups with higher minima. In the studies of VBB (1990) with 13 to 16 subjects the downward trend towards the lowest minimum takes place very quickly. In Bornstein, Gneezy, and Nagel (2002) the downward trend is much slower or even does not take place at all in some observations. That is, eventually the first period minima are stable enough such that Pareto-improving group switching behavior can occur.

The MedCT is the standard median effort game with fixed groups. Subjects interact in fixed groups of 9 subjects as in VBB (1991) and Cachon and Camerer (1996). The number of periods, the range of possible effort decisions, the payoff parameters, the exchange rate, and the lump sum payment were exactly the same as in MedGT. The only difference to the MedGT consisted in the historical data. Since in MedCT no other group was eligible, subjects received for all preceding rounds feedback only on their own effort decision, the median in their group, their period payoff, and finally their accumulated payoff.

Exchange rates were chosen to reach approximately the hourly student-wage in Germany. In the MedGT (MedCT) the exchange rate was 0.0027 Euros per ExCu. In the MinGT the exchange rate was equal to 0.006 Euros per ExCu. The total payoff of a subject in all treatments was the sum of the period payoffs. In order to avoid first period bankruptcies in the median effort treatments, we made an initial lump-sum payment of $500 \mathrm{ExCu}$ to the subjects. As in Bornstein, Gneezy, and Nagel (2002), subjects received in addition to the sum of the period payoffs a show up fee of 2 Euros upon arriving in MinGT.

The course of all experiments was as follows. Upon arriving, the identities of the participants were checked ${ }^{6}$. After all subjects had appeared for the respective session they were seated in separate cubicles facing a computer screen. Instructions and payoff tables were distributed and read aloud (see appendix B and C). Before subjects played the respective treatment on the computer they had to take a written test concerning their understanding of the instructions and the payoff table. Only after all subjects successfully completed the test, the respective treatment was started on the computer. The sessions ended with subjects filling out a questionnaire concerning their play. Finally subjects were paid their earnings in Euro.

The experiment took place at the lab of the economics department of Bonn in April, May and August 2004. In total, 300 subjects participated in 18 sessions. The average duration of a session was about 1 hour. The average payment was 7.09 Euros.

\footnotetext{
${ }^{6}$ The recruiting of subjects was done by the online recruiting system of Greiner (1998).
} 


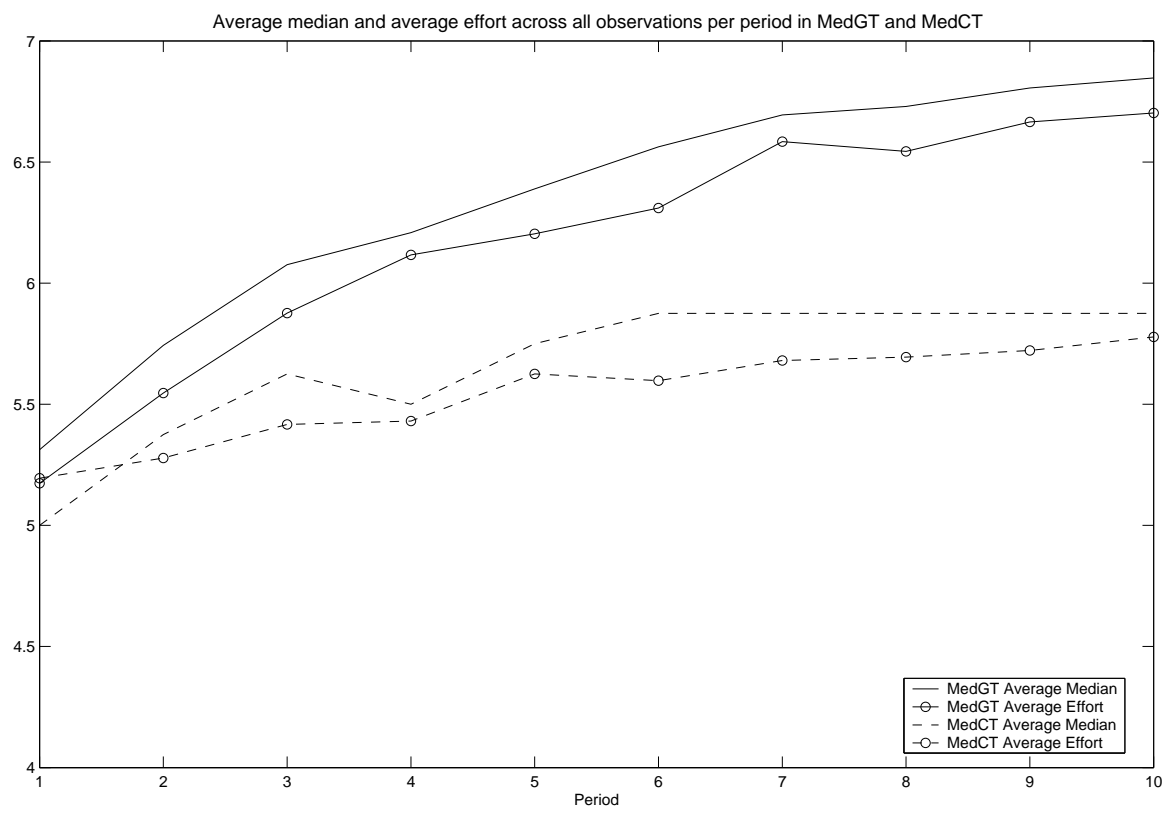

Figure 1: Average median and efforts.

\section{Results}

\subsection{Hypotheses 1 and 2 in the median effort game}

Test of hypothesis 1: Figure (1) shows the average median and average effort per period across the observations in the MedGT and the MedCT treatment ${ }^{7}$.

Both treatments started at about the same values. The average median across the 8 observations in MedCT was 5 while it was 5.3 in MedGT. Average efforts were even closer to each other and started at about the same value of 5.2. In the following periods, the difference between the two treatments increased almost in every period. While we observed a strong increase of the average median in MedGT to 6.9 in the tenth period, there was only a slight increase in MedCT to 5.9. The same divergence was observed for the average efforts. While they started about the same value as outlined above, the average effort is at 6.7 in MedGT but only at 5.8 in MedCT in period 10. The standard deviations of efforts in groups evolved very similarly in the two treatments. Similarly to above we weighted in every observation of MedGT the standard deviation of efforts of a group by its number of members in order to yield one value for the respective observation. The average standard deviation of efforts across the 8 observations in MedCT was 1.39 in the first period and 1.47 in MedGT. Up to the last period these values decreased almost in every period reaching 0.99 in the fifth period and 0.59 in the tenth period in MedCT. The corresponding values in MedGT were 0.72 and 0.44.

Tables (1) and (2) display for MedGT and MedCT, for each period, and for the medians 7, $6,5,4$ the number of groups with that particular median ((1) rows in the tables). Moreover,

\footnotetext{
${ }^{7}$ Since in MedGT we have two groups $X$ and $Y$ per observation, we determine the median of an observation $\overline{M e d}_{O b s}^{t}$ in a given period $t$ after the following formula: $\overline{M e d}_{O b s}^{t}=\frac{n_{X}^{t} M e d_{X}^{t}+n_{Y}^{t} M e d_{Y}^{t}}{N}$. That is, we weight the median $\left(\operatorname{Med}_{X}^{t}, M e d_{Y}^{t}\right)$ of a group by its number of members $\left(n_{X}^{t}, n_{Y}^{t}\right)$. We do the same in order to determine the average effort $\bar{E}_{\text {Obs }}^{t}$ in an observation.
} 
Table 1: Distribution of medians per period in MedGT

\begin{tabular}{|c|c|c|c|c|c|c|c|c|c|c|}
\hline Period & 1 & 2 & 3 & 4 & 5 & 6 & 7 & 8 & 9 & 10 \\
\hline 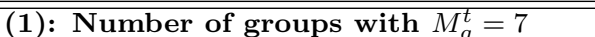 & 3 & 5 & 6 & 6 & 7 & 8 & 10 & 12 & 11 & $\overline{11}$ \\
\hline $\begin{array}{l}\text { (2): Percentage of subjects } \\
\text { in a group with } M_{a}^{t}=7\end{array}$ & 18.8 & 31.9 & 47.9 & 53.5 & 60.4 & 68.8 & 79.2 & 84.7 & 88.9 & 93.1 \\
\hline $\begin{array}{l}\text { (3): Percentage of all subjects in group } \\
M_{g}^{t}=7 \text { who played } e_{i_{g}}^{t}=7\end{array}$ & 55.6 & 63.0 & 78.3 & 83.1 & 89.7 & 86.9 & 92.1 & 90.2 & 93.8 & 91.8 \\
\hline (1): Number of groups with $M_{g}^{t}=6$ & 1 & 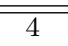 & 3 & 3 & 4 & 3 & 2 & 1 & 2 & 2 \\
\hline $\begin{array}{l}\text { (2): Percentage of subjects } \\
\text { in a group with } M_{g}^{t}=6\end{array}$ & 6.3 & 29.9 & 17.4 & 17.4 & 20.8 & 20.1 & 13.2 & 8.3 & 6.3 & 2.0 \\
\hline $\begin{array}{l}\text { (3): Percentage of all subjects in group } \\
M_{g}^{t}=6 \text { who played } e_{i_{g}}^{t}=6\end{array}$ & 22.2 & 30.2 & 52.0 & 52.0 & 53.3 & 48.3 & 63.2 & 75.0 & 77.8 & 100 \\
\hline (1): Number of groups with $M_{g}^{t}=5$ & 10 & 3 & 5 & 5 & 4 & 4 & 3 & 1 & 1 & 1 \\
\hline $\begin{array}{l}\text { (2): Percentage of subjects } \\
\text { in a group with } M_{g}^{t}=5\end{array}$ & 62.5 & 22.2 & 29.2 & 25.7 & 16.0 & 9.7 & 5.6 & 2.1 & 1.4 & 1.4 \\
\hline $\begin{array}{l}\text { (3): Percentage of all subjects in group } \\
M_{g}^{t}=5 \text { who played } e_{i_{g}}^{t}=5\end{array}$ & 31.1 & 40.6 & 45.2 & 45.9 & 69.6 & 64.3 & 75.0 & 100 & 100 & 100 \\
\hline (1): Number of groups with $M_{g}^{t}=4$ & 2 & 3 & 2 & 1 & 1 & 1 & 1 & 2 & 2 & 2 \\
\hline $\begin{array}{l}\text { (2): Percentage of subjects } \\
\text { in a group with } M_{g}^{t}=4\end{array}$ & 12.5 & 12.5 & 5.6 & 3.5 & 2.8 & 1.4 & 2.1 & 4.9 & 3.5 & 3.5 \\
\hline $\begin{array}{l}\text { (3): Percentage of all subjects in group } \\
M_{g}^{t}=4 \text { who played } e_{i_{g}}^{t}=4\end{array}$ & 31.1 & 40.6 & 45.2 & 45.9 & 69.6 & 64.3 & 75.0 & 100 & 100 & 100 \\
\hline
\end{tabular}

Remark: There are $\left(8^{*} 2=\right) 16$ groups and $\left(8^{*} 18=\right) 144$ subjects in total participating in MedGT.

Table 2: Distribution of medians per period in MedCT

\begin{tabular}{|c|c|c|c|c|c|c|c|c|c|c|}
\hline Period & 1 & 2 & 3 & 4 & 5 & 6 & 7 & 8 & 9 & 10 \\
\hline (1): Number of groups with $M_{g}^{t}=7$ & 1 & 2 & 3 & 2 & 3 & $\overline{4}$ & 4 & 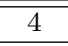 & $\overline{4}$ & 4 \\
\hline $\begin{array}{l}\text { (2): Percentage of subjects } \\
\text { in a group with } M_{g}^{t}=7\end{array}$ & 12.5 & 25.0 & 37.5 & 25.0 & 37.5 & 50.0 & 50.0 & 50.0 & 50.0 & 50.0 \\
\hline $\begin{array}{l}\text { (3): Percentage of all subjects in group } \\
M_{g}^{t}=7 \text { who played } e_{i_{g}}^{t}=7\end{array}$ & 66.7 & 66.7 & 66.7 & 77.8 & 74.1 & 75.0 & 80.6 & 86.1 & 91.7 & 83.3 \\
\hline (1): Number of groups with $M_{g}^{t}=6$ & 1 & 2 & 1 & 2 & 2 & 1 & 1 & 1 & 1 & 1 \\
\hline $\begin{array}{l}\text { (2): Percentage of subjects } \\
\text { in a group with } M_{g}^{t}=6\end{array}$ & 12.5 & 25.0 & 12.5 & 25.0 & 25.0 & 12.5 & 12.5 & 12.5 & 12.5 & 12.5 \\
\hline $\begin{array}{l}\text { (3): Percentage of all subjects in group } \\
M_{g}^{t}=6 \text { who played } e_{i_{g}}^{t}=6\end{array}$ & 11.1 & 38.9 & 33.3 & 44.4 & 27.8 & 44.4 & 55.6 & 55.6 & 77.8 & 66.7 \\
\hline (1): Number of groups with $M_{g}^{t}=5$ & 3 & 1 & 2 & 2 & 1 & 1 & 1 & 1 & 1 & 1 \\
\hline $\begin{array}{l}\text { (2): Percentage of subjects } \\
\text { in a group with } M_{g}^{t}=5\end{array}$ & 37.5 & 12.5 & 25.0 & 25.0 & 12.5 & 12.5 & 12.5 & 12.5 & 12.5 & 12.5 \\
\hline $\begin{array}{l}\text { (3): Percentage of all subjects in group } \\
M_{g}^{t}=5 \text { who played } e_{i_{g}}^{t}=5\end{array}$ & 25.9 & 22.2 & 27.8 & 38.9 & 77.8 & 66.7 & 77.8 & 88.9 & 77.8 & 88.9 \\
\hline (1): Number of groups with $M_{g}^{t}=4$ & 3 & 3 & 2 & 2 & 2 & 2 & 2 & 2 & 2 & 2 \\
\hline $\begin{array}{l}\text { (2): Percentage of subjects } \\
\text { in a group with } M_{g}^{t}=4\end{array}$ & 37.5 & 37.5 & 25.0 & 25.0 & 25.0 & 25.0 & 25.0 & 25.0 & 25.0 & 25.0 \\
\hline $\begin{array}{l}\text { (3): Percentage of all subjects in group } \\
M_{g}^{t}=4 \text { who played } e_{i_{g}}^{t}=4\end{array}$ & 44.4 & 51.9 & 50.0 & 88.9 & 66.7 & 88.9 & 83.3 & 83.3 & 72.2 & 83.3 \\
\hline
\end{tabular}

Remark: There are 8 groups and $\left(8^{*} 9=\right) 72$ subjects in total participating in MedCT. 
they give the percentages of all subjects in the respective treatment who were in a group with the particular median (rows (2) in the tables). Finally, table (1) and (2) give the percentage of all subjects in a particular median group who played their effort $e_{i_{g}}^{t}$ equal to their group median $M_{g}^{t}$ (rows (3) in the tables) ${ }^{8}$.

Looking at the rows (3) in table (1) and (2) confirms that the decline of the standard deviations of group efforts mentioned above is indeed due to convergence. That is, more and more subjects chose an effort equal to the group median as time goes by. In the first period, effort compliance rates with the actual median started at considerably higher values for those groups with median 7 (55.6\% in MedGT and $66.7 \%$ in MedCT) than for those with lower medians $(22.2 \%$ to $31.1 \%$ in MedGT and $11.1 \%$ to $44.4 \%$ in MedCT).

Tables (1) and (2) shed more light on the nature and magnitude of upward coordination in the two treatments. Treatment MedGT started with 3 observations having one group achieving a median of 7 in period 1. Since group size was fixed in the very first period, this corresponds to $18.8 \%$ of all subjects participating in MedGT. The majority of subjects $(62.5 \%, 10$ groups) started in a group with median 5 in period 1. 12.5\% of all subjects in MedGT (2 groups) were in a group with median 4 in period 1 . Beside the 3 observations just mentioned above, 2 observations started with both groups having a median of 5 . The three remaining observations in MedGT had different medians in the two groups in the first period but both medians being lower than 7 .

The starting point in MedCT looks very similarly. One observation (i.e. $12.5 \%$ of all subjects in MedCT since group sizes are fixed to 9 subjects throughout an observation) started at median 7 . The remaining 7 observations started at a median lower than 7 . The majority of observations began with a median of 5 or 4 .

In period $6 \mathrm{MedCT}$ reached its final constellation of medians across the observations. Three observations display the typical coordination failure as observed in VanHuyck, Battalio, and Beil (1991) and by other authors: The median of the first period had not changed and it was 4 or 5 . Moreover, up to the last period more and more subjects adjusted their effort to the group median. In period 10 the group which coordinated on median five had $88.9 \%$ of the subjects playing their effort equal to median. In the two groups with median four $83.3 \%$ of the subjects chose the equilibrium effort. In contrast to VanHuyck, Battalio, and Beil (1991) subjects in one observation of MedCT were successful to coordinate upward from median 4 to median 6 still displaying coordination failure. However, 4 observations had a median of 7 from period 6 on. In three of these observations subjects were successful to coordinate upward from a median of 5 or 6 , while one observation started already at 7 like mentioned above.

In contrast to treatment MedCT Pareto-improvements took place up the very last period in treatment MedGT. Moreover, considerably more subjects (93.1\%) in MedGT ended up in a group with median 7 (only 50\% in treatment MedCT). In MedGT there was at least one group in every observation achieving a median of 7 from the 8 th period on. In 3 of the 8 observations both groups had a median of 7 as predicted by the myopic best reply process in section 3 . In the remaining 5 observations a small fraction of subjects (1 to 3 subjects in each observation, i.e. $6.9 \%$ of all subjects in MedGT) remained in the group with the lower median till the end. Surprisingly, these subjects did not switch to the group which had established median 7 in the preceding periods. One might argue that some subjects did not understand the rules of the game, or that they did not care and played anything. However, in period nine 4 of these 5 groups reached a "within group" - equilibrium outcome, i.e. all players in the lower median

\footnotetext{
${ }^{8}$ A lower median than 4 was only observed in one period of an observation in MedGT.
} 
group played an effort equal to median of the group.

Figure (1) and tables (1) and (2) give clear evidence for stronger welfare improvements in the treatment under endogenous group formation (MedGT) as compared to the fixed group setting (MedCT). In fact, if we compare the percentage increases of subjects in a group with median 7 from period 5 to period 10 in the observations of MedGT with the same increases in MedCT we get a significant difference for the two treatments. The Wilcoxon-Mann-Whitney test (see Siegel and Castellan (1988)) yields a significance level of 0.01.

However, the Wilcoxon-Mann-Whitney test yields no significant difference between the 8 medians in MedCT in period 10 and the 8 medians $\overline{M e d}_{\text {Obs }}^{t}$, calculated as for figure 1 in MedGT. This is due to the fact that 4 observations in MedCT yield a median of 7 in period 10 .

Result 1 We find some evidence for hypothesis 1. Period 1 values of efforts and medians looked quite similar in both treatments. Over time, however, endogenous group formation in MedGT caused strong Pareto-improvements as compared to the treatment with fixed groups in $\operatorname{Med} C T$.

Evidence for hypothesis 2: In section 3 we proposed a simple myopic best reply dynamic which leads to the payoff dominant equilibrium under endogenous group formation. In the following we investigate if subjects indeed played according to their myopic best reply.

For this purpose, we calculate for every subject in MedGT and for period $t=2,3, \ldots, 10$ the theoretical myopic best reply (MBR) of section 3. That is, given the actual values of medians and group sizes in period $t-1$ of group $X$ and $Y$ we calculate the best reply for every player to that values ${ }^{9}$. We then investigate how actual group and effort decisions in period $t$ conformed or deviated from the predicted MBR values. As mentioned before, in MedGT we determined one of the two "middle" numbers at random when groups had an equal number of participants in a certain period. Calculating the myopic best replies for a period $t$ we accounted for this random rule assuming risk neutrality ${ }^{10}$.

Figure (2) displays the percentage of all subjects in period $t$ who took their group decision according the the myopic best reply and chose an effort strictly larger, equal, or strictly smaller than the myopic best reply effort (STRICTLY LARGER MBR, TRUE MBR, STRICTLY SMALLER MBR-line). It also gives the percentage of subjects in MedGT who took their actual group decision in period $t$ departing from the MBR group decision (NOT GROUP MBR-line). In particular, it includes those subjects who switch or stick to a group with a lower median although a costless switch to a higher median group is available.

Figure (2) shows that a considerable amount of subjects deviated in the very first periods from myopic best reply. While the majority of subjects took their group decision according to the myopic best reply rule (NOT GROUP MBR reached its peak in period $3(32 \%)$ and almost steadily decreased thereafter to $7 \%$ in period 10), effort decisions were more dispersed.

\footnotetext{
${ }^{9}$ For the case of indifference between the two groups (see assumption 2 of section 3 ) each of the two groups may be chosen.

${ }^{10}$ As mentioned before, according to the myopic best reply, players switch to an empty group and choose the maximal effort. Moreover, straightforward calculations show that under the random rule and given the particular payoff table in MedGT, players switch to a one player group if this group has a median which is as least as high as the median in the own group. In particular, they choose an effort which lies one unit above the median of the one player group as long as this rule does not exceed the maximum effort $\bar{e}$, choosing the maximum effort otherwise. As outlined before, the result of coordination on the payoff dominant solution of the evolutionary dynamics presented in section 3 also holds under the random rule and all kind of risk attitudes. Basically the noise assumption guarantees the emergence of an empty group with some positive probability which in turn triggers coordination on the maximum median.
} 


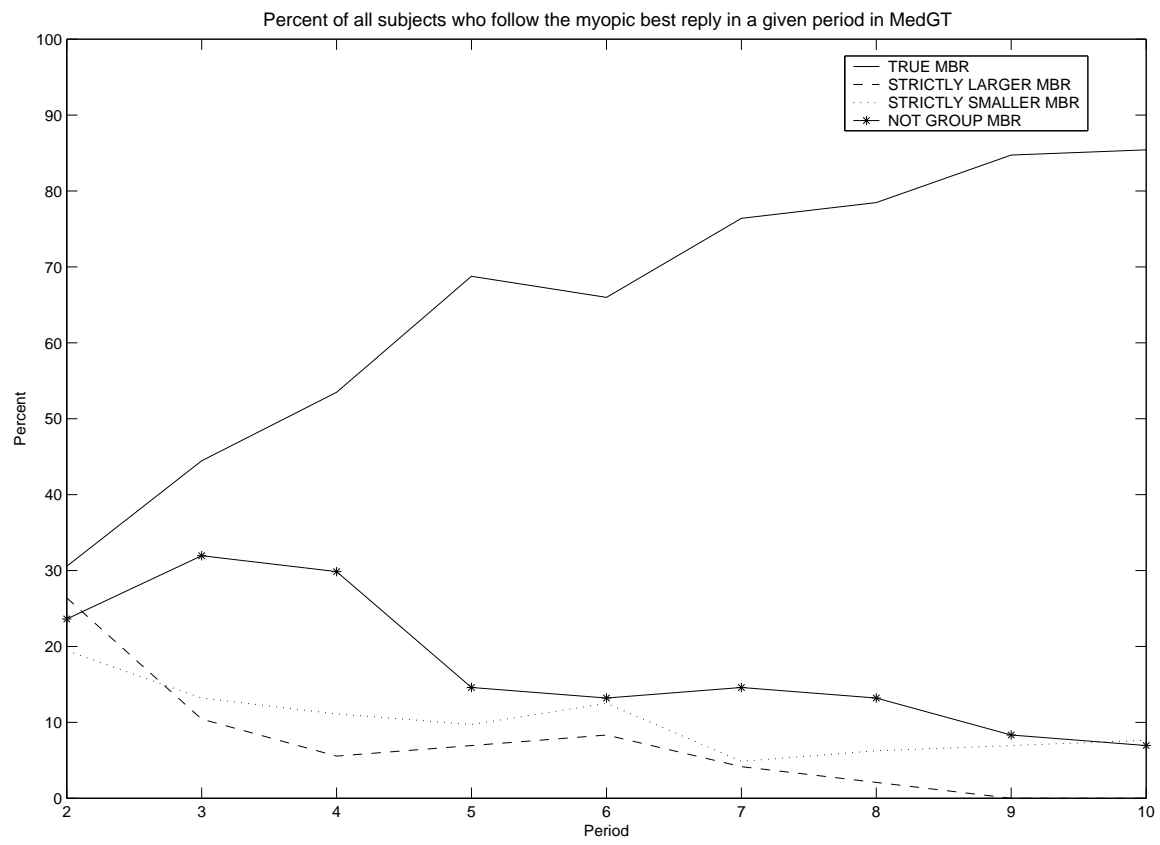

Figure 2: Myopic best replies in MedGT.

In period two, $31 \%$ of all subjects took their group decision and their effort decision exactly according to the the myopic best reply prediction. $26 \%(19 \%)$ also followed the myopic best reply group decision but chose a strictly higher (lower) effort level. As the play reached the maximum median 7 in more and more observations the TRUE MBR- line increased up to $85 \%$ while the STRICTLY LARGER MBR-line naturally decreased to $0 \%$. That is, more and more players adopted the myopic best reply as coordination settled down on the maximum median. Nevertheless, the figure (2) also shows that in all periods a small fraction of subjects did not switch to the myopic best reply decision. Either some subjects did choose a group different from the myopic best reply group (that is they did not switch to the group with the higher median) or they chose a lower effort (in the 10th period the respective percentages are $7 \%$ and $8 \%)$.

Result 2 More and more subjects followed exactly the myopic best response as periods elapsed. In the very first periods, however, behavior was more dispersed. Pareto-improvements in MedGT, therefore, took more periods than predicted by a pure myopic best reply process. 


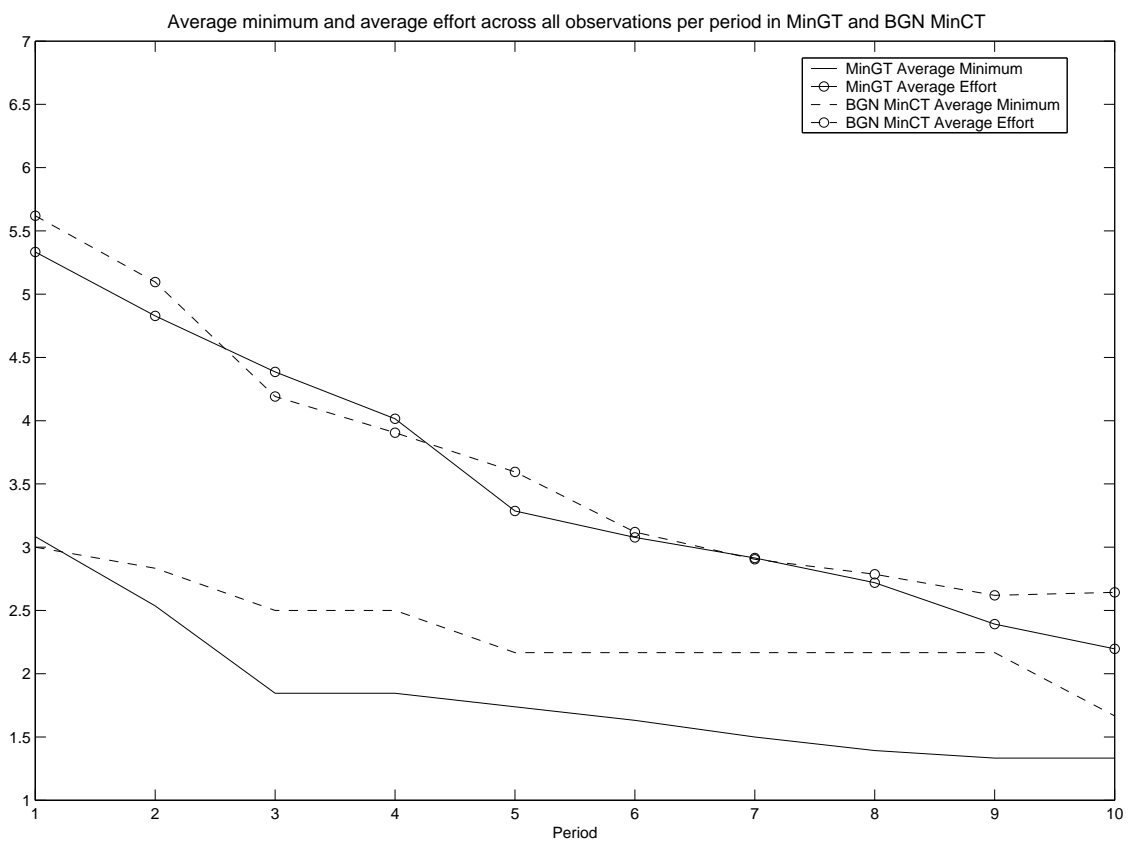

Figure 3: Average minima and efforts.

\subsection{Hypotheses 1 and 2 in the minimum effort game}

Test of hypothesis 1: While first period behavior was very similar in both MinGT and MedGT, results in the MinGT treatment differ completely from the ones in MedGT in the course of play. Figure (3) displays the average minimum and average effort across the 6 observations in MinGT (MinGT Average Minimum and MinGT Average Effort - line) ${ }^{11}$. In addition, figure (3) also plots the average minimum and average effort across the 6 observations of the minimum effort game treatment with fixed groups of Bornstein, Gneezy, and Nagel (2002) (in the following BGN MinCT). Our treatment MinGT only differs from BGN MinCT with respect to the endogenous group formation possibility. All other design features like the payoff parameters, the length of interaction, exchange rate,... are the same.

In contrast to MedGT, figure (3) displays a steady decline of average minimum and average efforts for the MinGT treatment. Both statistics decreased from period to period. While the average effort (5.3) started about the same value as in MedGT, the average minimum across observations lay at 3.1 in period 1 . In period 10 the average minimum had reached 1.3 while the average effort had declined to 2.2 .

The data of Bornstein, Gneezy, and Nagel (2002) displayed a very similar pattern to our MinGT treatment (BGN MinCT Average Minimum and BGN MinCT Average Effort - line). Average efforts in BGN MinCT had almost the same course than average efforts in MinGT. The average minimum line in BGN started at about the same value as in MinGT (3.0) but remained somewhat above the average minimum line in MinGT. From period 5 to 9 it reached a value of 2.17 falling to 1.67 in the last period. Non-parametric tests like the Wilcoxon-MannWhitney test or the robust rank order test do not yield a significant difference in any period

\footnotetext{
${ }^{11}$ We calculated the minimum of an observation $\overline{M i n}_{\text {Obs }}^{t}$ given a period $t$ in the same fashion as we did for MedGT $\left(\overline{\operatorname{Min}}_{\mathrm{Obs}}^{t}=\frac{n_{X}^{t} \operatorname{Min}_{X}^{t}+n_{Y}^{t} \operatorname{Min}_{Y}^{t}}{N}\right)$. Also the average effort of an observation $\bar{E}_{O b s}^{t}$ was calculated as in MedGT.
} 
Table 3: Distribution of minima per period in MinGT

\begin{tabular}{|c|c|c|c|c|c|c|c|c|c|c|}
\hline Period & 1 & 2 & 3 & 4 & 5 & 6 & 7 & 8 & 9 & 10 \\
\hline (1): Number of groups with $\operatorname{Min}_{g}^{t}=4$ & 6 & 3 & 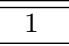 & $\overline{1} 1$ & 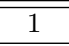 & 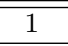 & 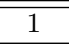 & 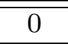 & 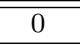 & 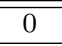 \\
\hline $\begin{array}{l}\text { (2): Percentage of subjects } \\
\text { in a group with } \operatorname{Min}_{g}^{t}=4\end{array}$ & 50.0 & 23.8 & 8.3 & 4.8 & 6.0 & 7.1 & 10.7 & 0 & 0 & 0 \\
\hline $\begin{array}{l}\text { (3): Percentage of all subjects in group } \\
\text { Min }_{g}^{t}=4 \text { who played } e_{i_{g}}^{t}=4\end{array}$ & 16.7 & 35.0 & 14.3 & 50.0 & 20.0 & 66.7 & 55.6 & - & - & - \\
\hline (1): Number of groups with $\operatorname{Min}_{g}^{t}=3$ & 3 & 4 & 3 & 4 & 3 & 2 & 1 & 2 & 2 & 2 \\
\hline $\begin{array}{l}\text { (2): Percentage of subjects } \\
\text { in a group with } \operatorname{Min}_{g}^{t}=3\end{array}$ & 25.0 & 32.1 & 27.4 & 31.0 & 22.6 & 15.5 & 6.0 & 16.7 & 16.7 & 16.7 \\
\hline $\begin{array}{l}\text { (3): Percentage of all subjects in group } \\
\operatorname{Min}_{g}^{t}=3 \text { who played } e_{i_{g}}^{t}=3\end{array}$ & 28.6 & 22.2 & 17.4 & 19.2 & 26.3 & 15.4 & 20.0 & 21.4 & 14.3 & 50.0 \\
\hline (1): Number of groups with $\operatorname{Min}_{g}^{t}=2$ & 1 & 2 & 1 & 1 & 1 & 1 & 1 & 1 & 0 & 0 \\
\hline $\begin{array}{l}\text { (2): Percentage of subjects } \\
\text { in a group with } \operatorname{Min}_{g}^{t}=2\end{array}$ & 8.3 & 17.9 & 4.8 & 8.3 & 10.7 & 10.7 & 6.0 & 6.0 & 0 & 0 \\
\hline $\begin{array}{l}\text { (3): Percentage of all subjects in group } \\
\operatorname{Min}_{g}^{t}=2 \text { who played } e_{i_{g}}^{t}=2\end{array}$ & 28.6 & 13.3 & 50.0 & 14.3 & 11.1 & 11.1 & 60.0 & 20 & - & - \\
\hline$\overline{(1): ~ N u m b e r}$ of groups with $\operatorname{Min}_{g}^{t}=1$ & 2 & 3 & 7 & 6 & 7 & 8 & 9 & 9 & 10 & 10 \\
\hline $\begin{array}{l}\text { (2): Percentage of subjects } \\
\text { in a group with } \operatorname{Min}_{g}^{t}=1\end{array}$ & 16.7 & 26.2 & 59.5 & 56.0 & 60.7 & 66.7 & 77.4 & 77.4 & 83.3 & 83.3 \\
\hline $\begin{array}{l}\text { (3): Percentage of all subjects in group } \\
\operatorname{Min}_{g}^{t}=1 \text { who played } e_{i_{g}}^{t}=1\end{array}$ & 14.3 & 13.6 & 16.0 & 21.3 & 39.2 & 46.4 & 43.1 & 55.4 & 62.9 & 64.3 \\
\hline
\end{tabular}

Remark: There are $\left(6^{*} 2=\right) 12$ groups and $\left(6^{*} 14=\right) 84$ subjects in total participating in MinGT.

between the minima $\overline{M i n}_{\text {Obs }}^{t}$ in MinGT and the minima in BGN MinCT. The same holds for the comparison of average efforts in the two treatments. If anything, endogenous group formation accelerated the decay of minima.

The difference between MinGT on the one hand and MedGT on the the other hand concerning average efforts and medians/minima becomes strongly significant in the course of play. Only in period one the Wilcoxon-Mann-Whitney test does not reject the null hypothesis that the 6 average efforts $\bar{E}_{\text {Obs }}^{1}$ in MinGT have been drawn from the same distribution as the 8 average efforts $\bar{E}_{O b s}^{1}$ in MedGT $(\mathrm{p}=55 \%)$. In all other periods the test yields rejection of the null hypothesis at 0.02 and lower significance levels. In fact, in each period after the third, all 6 average efforts $\bar{E}_{\text {Obs }}^{t}$ in MinGT were smaller than the smallest average effort $\bar{E}_{\text {Obs }}^{t}$ in MedGT. Moreover, in every period the 6 minima $\overline{\operatorname{Min}}_{\text {Obs }}^{t}$ were always smaller than the smallest median of the 8 medians $\overline{M e d}_{O b s}^{t}$ in MedGT.

Result 3 In contrast to MedGT in MinGT we cannot find any support for Pareto-improving coordination under endogenous group formation as hypothesis 1 postulates. The results in MinGT are not significantly different to interaction in fixed groups in BGN MinCT.

The development of the average standard deviation of efforts turns out to be another difference between MinGT/BRN MinCT on the one hand and MedGT on the other hand. Calculation of the standard deviation of efforts in MinGT was done as in MedGT. While this statistics decreased in MedGT, it remained almost constant across periods in MinGT (BRN MinCT). It started at about the same value as in MedGT at 1.53 (1.64) but fluctuated around 1.4 (1.0), reaching 1.3 (1.1) in the last period.

In analogy to MedGT and MedCT, table (3) displays for each period the number of groups in MinGT having their minimum equal to $4,3,2$, or 1 (rows (1) in table (3). It also gives the percentage of all subjects in MinGT which are in a group with the respective minimum (rows (2)). Finally, it gives the percentage of all subjects in a group with a certain minimum who 
Table 4: First period effort distribution in MedGT, MinGT and BGN MinCT

\begin{tabular}{|l|c|c|c|c|c|c|c|}
\hline Effort & $\mathbf{1}$ & $\mathbf{2}$ & $\mathbf{3}$ & $\mathbf{4}$ & $\mathbf{5}$ & $\mathbf{6}$ & $\mathbf{7}$ \\
\hline \hline MedGT (\%) & 1 & 3 & 8 & 25 & 22 & 13 & 18 \\
\hline MinGT (\%) & 2 & 4 & 10 & 12 & 20 & 20 & 32 \\
\hline BGN MinCT (\%) & 2 & 0 & 12 & 19 & 2 & 14 & 50 \\
\hline
\end{tabular}

actually chose their effort equal to their group minimum in the respective period (rows (3)). The table shows that no group in MinGT ever exceeded a minimum of 4 . In the following, we first turn to period one outcomes. In the first period half of the 12 groups in MinGT started with a minimum of 4, i.e. 6 groups. Since group size in the first period was fixed to 7 subjects this corresponds to half of the subjects in MinGT. 4 observations had one group with minimum 4 and the other group with minimum 3, 2, or 1 . One observation started with both groups at minimum 4 . The sixth observation had both groups with lower minima than 4 (1 and 3). Table (3) shows that the first period minima in all groups were determined only by a minority of participants. For groups with minima 2 and 3 only $28.6 \%$ of all subjects in such groups played an effort equal to the actual minimum. For groups with minima 1 and 4 these percentages are even lower $(14.3 \%$ and $16.7 \%)$. That is, the majority of subjects chose a higher effort than the realized minima.

The picture is very similar in the BGN MinCT data. Except one period where a group reached a minimum of 5 , no group reached a higher minimum than 4 in any period. In the first period of BGN MinCT there were two groups which started at minimum 4, three at 3 and one at minimum 1. Like in MinGT only a small fraction (16.7\%) of all subjects in BGN MinCT determined the first period minimum with their effort.

Interestingly, the distribution of efforts in MinGT, BGN MinCT and MedGT in period 1 was almost the same (see table (4) ). In all three treatments the first three effort levels have a low frequency in the first period.

For period 2 to 10 table (3) illustrates in more detail the decay of minima and the increasing coordination failure in MinGT as seen in figure (3). The number of observations with both minima at 1 increased almost steadily in time. From period 9 on 5 observations had in both groups a minimum of 1 . That is $83.3 \%$ of all subjects in MinGT ended up in a group with the lowest minimum. Only in one observation both groups coordinated on a minimum of 3. Groups with minima 2 (4) became extinct from period 9 (8) on. This result completely contrasts the result in terms of coordination failure made in MedGT. 91.8\% of all subjects in that latter treatment ended up in a group with the payoff dominant median 7 .

As the comparison of average standard deviations of efforts suggested, another difference between MedGT and MinGT is convergence. While in period ten $90 \%$ of all subjects in MedGT chose their effort equal to the group median only $62 \%$ do so in MinGT. That is, $38 \%$ continued to choose a higher effort in the last period although play had settled at the lowest minimum some periods before in most of the observations. In fact, we did not observe one equilibrium outcome in MinGT. Even though the group minima were the same in all observations in the last periods, there was always at least one subject deviating from the actual group minimum. The coordination failure in BGN MinCT with fixed groups displays a similar form as in MinGT. From the 6th period onwards the observations with minimum 3 became extinct. Three observations reached a minimum of 1 . One observation had a minimum of 2 , and two a minimum of 4 . In the last period one of the two latter groups coordinated also on minimum 1 in the 10th period. Convergence to actual group minima was similar than in MinGT. Only 
Table 5: Last period effort distribution in MedGT, MinGT, and BGN MinCT

\begin{tabular}{|l|c|c|c|c|c|c|c|}
\hline Effort & $\mathbf{1}$ & $\mathbf{2}$ & $\mathbf{3}$ & $\mathbf{4}$ & $\mathbf{5}$ & $\mathbf{6}$ & $\mathbf{7}$ \\
\hline \hline MedGT (\%) & 0 & 0 & 1 & 3 & 3 & 7 & 85 \\
\hline MinGT (\%) & 54 & 17 & 12 & 12 & 4 & 0 & 2 \\
\hline BGN MinCT (\%) & 40 & 14 & 7 & 29 & 2 & 2 & 5 \\
\hline
\end{tabular}

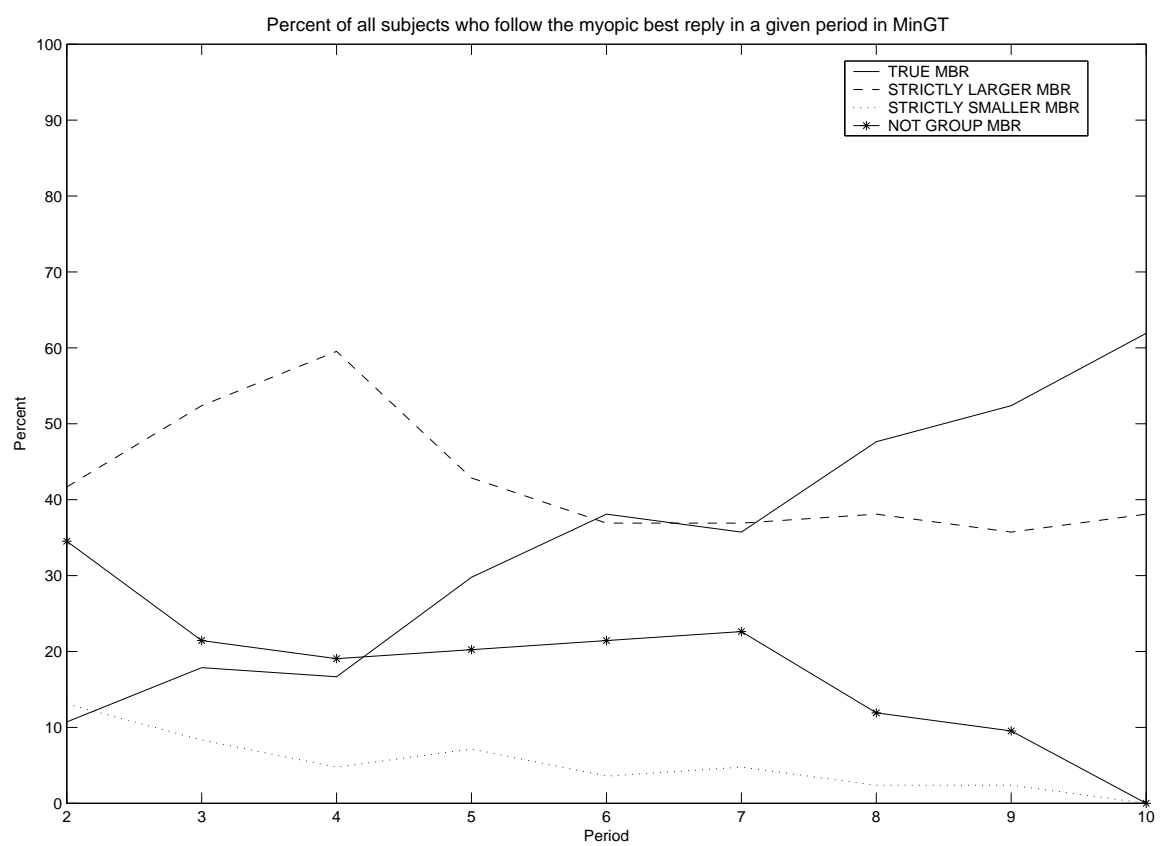

Figure 4: Myopic best replies in MinGT.

$67 \%$ had their own effort equal to the group minimum of the observation. Like in MinGT this led to very few equilibrium outcomes in BGN MinCT. Only one to two groups were in equilibrium in the last three periods.

To complete the picture table (5) depicts the distribution of efforts in the three treatments in the last period.

Comparing table (5) to table (4) makes again clear that the strategic environment is crucial for the coordination outcome under endogenous group formation. While $85 \%$ of all players in MedGT ended up choosing an effort of 7 and none an effort of 1 or 2, the outcome was completely different in MinGT/BGN MinCT. Almost no player chose an effort of 6 or 7 in these treatments while the majority of subjects selected an effort of 1 or 2 .

Evidence for hypothesis 2: Subjects in MinGT were not successful in coordinating upwards. That is, there must have been deviations from the proposed myopic best reply process. Figure (4) is set up for the MinGT in analogous fashion to figure $(2)^{12}$.

\footnotetext{
${ }^{12}$ We first calculate for all minima and group sizes of period $t-1$ the myopic best reply (MBR) in period $t$. As in MedGT each of the two groups may be chosen in case of indifference (see assumption 2). Next, we identify the percentage of actual decisions in every period $t$ which coincide with the MBR group decision and the MBR effort decision for the respective subject (TRUE MBR). We also give the percentages of decisions where actual group decision and MBR decisions are identical but actual effort choices are strictly larger (STRICTLY LARGER MBR) or strictly smaller (STRICTLY SMALLER MBR). Finally we give the percentage of actual group decisions which are not in line with the MBR group decision (NOT GROUP MBR).
} 
Figure (4) shows that, as in MedGT, those subjects who took their group decision according the the myopic best reply but chose a strictly lower effort formed the minority of all subjects (The STRICTLY SMALLER MBR-line started at $13 \%$ in period 2 and naturally deceased to $0 \%$ in period 10 as more and more observations settled down on the lowest minimum in both groups). Due to the different summary statistics in MedGT and MinGT those players had a negligible impact in MedGT. In MinGT however, they are responsible for the decay of coordination. One player is sufficient to determine the minimum.

As in MedGT, more and more subjects followed exactly the myopic best response as play reached the lowest minima in both groups and the remaining periods to play elapsed. The TRUE MBR-line in MinGT started at $11 \%$ and almost constantly increased up to $62 \%$ in period 10. However, these percentages were in each period lower than in MedGT. Looking at the STRICTLY LARGER MBR-line mainly explains this difference. A more or less constant fraction of all subjects (about 40\%) followed the myopic best reply with respect to the group decision but chose a strictly higher effort. That is, even though coordination deteriorated in the preceding periods a constant fraction of subjects tried to improve coordination.

The NON GROUP MBR-line in MinGT captures acyclic behavior: Players remained or switched to the group with the lower minimum in the preceding period, even though its group size was large. From period 3 to 7 about $20 \%$ of all subjects behaved in that way. As play converged to the same minima in all observations the NON GROUP MBR-line naturally decreased to $0 \%$ in period 10 .

Result 4 Only a minority of all subjects in MinGT followed exactly the myopic best response in the very first periods. About $40 \%$ tried persistently to improve the coordination result. A small fraction chose lower efforts than the myopic best reply efforts and thereby caused coordination failure.

\subsection{Group changes and the evolution of group sizes}

Table (6) and (7) reveal in more detail the nature of group changes in both the median (MedGT) and minimum effort game (MinGT). All rows display average group changes per period across the observations. The first row ((1) Av. Change) in each table displays the average group change. Row (2) indicates the average change to the group with the higher median (minimum) in the preceding period, row $(3)$ gives the average change even though the medians (minima) in the preceding period were the same, row (4) gives the average change to the group with the lower median (minimum), and row (5) reports the average group change to the group with the lower median (minimum), if this group also had the lower number of players. Finally, row (6) displays the percentage of all group changes explained by categories $(2),(3)$, and (5).

18 subjects participated in one observation of MedGT. Table (6) shows that in each of the first five periods at least 4.0 subjects changed the group on average in each observation. The group changes decreased as the remaining periods elapsed. Across all periods 3.5 group switches occurred in an observation on average per period. The table also reveals that group changes to the group with the higher median in the preceding period explain the majority of group changes in most of the periods. E.g. in period 2 we have 5.7 group changes on average across observations. Of these 5.7 group changes, 4.0 were changes to the group with the higher median in the preceding round. On average across all periods and all observations 2.0 subjects in each

period made such a group switch. As will be seen below, this behavior was responsible for 
Table 6: Group changes in MedGT

\begin{tabular}{|c|c|c|c|c|c|c|c|c|c|c|}
\hline Period & 2 & 3 & 4 & 5 & 6 & 7 & 8 & 9 & 10 & Averages \\
\hline (1): Av. Change & 5.7 & 4.5 & 4.0 & 4.0 & 4.0 & 3.2 & 2.0 & 3.0 & 1.0 & 3.5 \\
\hline (2): Av. change to higher median & 4.0 & 3.0 & 1.8 & 1.5 & 2.3 & 2.3 & 0.3 & 2.0 & 0.7 & 2.0 \\
\hline (3): Av. change same medians & 0.7 & 0.0 & 0.0 & 1.5 & 1.0 & 0.0 & 0.5 & 0.7 & 0.3 & 0.5 \\
\hline (4): Av. change to lower median & 1.0 & 1.5 & 2.2 & 1.0 & 0.7 & 0.8 & 1.2 & 0.3 & 0.0 & 1.0 \\
\hline $\begin{array}{l}\text { (5): Av. change to smaller group } \\
\text { with lower median }\end{array}$ & 0.0 & 1.3 & 2.2 & 1.0 & 0.5 & 0.7 & 1.2 & 0.0 & 0.0 & 0.8 \\
\hline$(6):((2)+(3)+(5)) /(1)$ & $82 \%$ & $96 \%$ & $100 \%$ & $100 \%$ & $96 \%$ & $95 \%$ & $100 \%$ & $89 \%$ & $100 \%$ & $94 \%$ \\
\hline
\end{tabular}

Table 7: Group changes in MinGT

\begin{tabular}{|c|c|c|c|c|c|c|c|c|c|c|}
\hline Period & 2 & 3 & 4 & 5 & 6 & 7 & 8 & 9 & 10 & Averages \\
\hline (1): Av. Change & 5.2 & 4.2 & 5.7 & 6.3 & 5.8 & 6.0 & 5.2 & 5.7 & 5.2 & 5.5 \\
\hline (2): Av. change to higher minimum & 2.8 & 1.5 & 2.7 & 2.7 & 2.2 & 1.3 & 1.0 & 0.8 & 0.0 & 1.7 \\
\hline (3): Av. change same minima & 0.5 & 2.0 & 2.5 & 3.0 & 3.0 & 3.8 & 3.8 & 4.2 & 5.2 & 3.1 \\
\hline (4): Av. change to lower minimum & 1.8 & 0.7 & 0.5 & 0.7 & 0.7 & 0.8 & 0.3 & 0.7 & 0.0 & 0.7 \\
\hline $\begin{array}{l}\text { (5): Av. change to smaller group } \\
\text { with lower minimum }\end{array}$ & 0.0 & 0.0 & 0.3 & 0.0 & 0.0 & 0.3 & 0.3 & 0.0 & 0.0 & 0.1 \\
\hline$(6):((2)+(3)+(5)) /(1)$ & $65 \%$ & $84 \%$ & $97 \%$ & $90 \%$ & $89 \%$ & $92 \%$ & $100 \%$ & $88 \%$ & $100 \%$ & $90 \%$ \\
\hline
\end{tabular}

the emergence of large groups in most of the observations of MedGT. From the moment that one of the two groups had reached median 7, the majority started to migrate to that group, and remained in that group up to the last period. There are periods where group changes to the group with higher median explain only a minor part of all switches (e.g. period 4 and 8). In these periods, group changes to the group with the lower median which also had the lower number of players in the preceding period explain almost all switches different from the former category. In period four, 2.2 from 4.0 group changes on average across observations are such changes. In period eight, 1.2 from 2.0 fit into this pattern. Note by comparing row (4) to row (5) that these changes explain almost all of the changes to a group with the lower median. This kind of behavior is in line with the predicted dynamics in section 3, i.e. changes to a group with a lower median only occur if this group also has the lower number of subjects. Finally, table (6) reveals that two equal medians in the preceding period trigger only a few group changes.

Remember that in contrast to MedGT not 18 but only 14 subjects participated in an observation of MinGT. Nevertheless, the average number of group changes across all observations and all periods given in row (1) was substantially higher than in MedGT (5.5 versus 3.5).

In particular the average group changes per period in the observations did not decrease in time in MinGT as they did in MedGT. This makes them higher in all periods except the first two periods. This is somehow surprising because play settled down at the lowest minimum in both groups in more and more observations. Nevertheless, group changes continued to occur. That is why the numbers in row (3) (group changes that occurred even though the minima in the preceding period have been the same) increased in time. Note that in contrast to MedGT these kind of group changes explain the major part of group switches (on average across all periods, 3.1 of 5.5 group changes per observation had this characteristic). Of course, convergence towards the same minima also explains why the average group changes to the higher minimum or to the lower minimum decreased in time.

Figure (5) and (6) show how group changes affected group sizes in MedGT and MinGT. We 


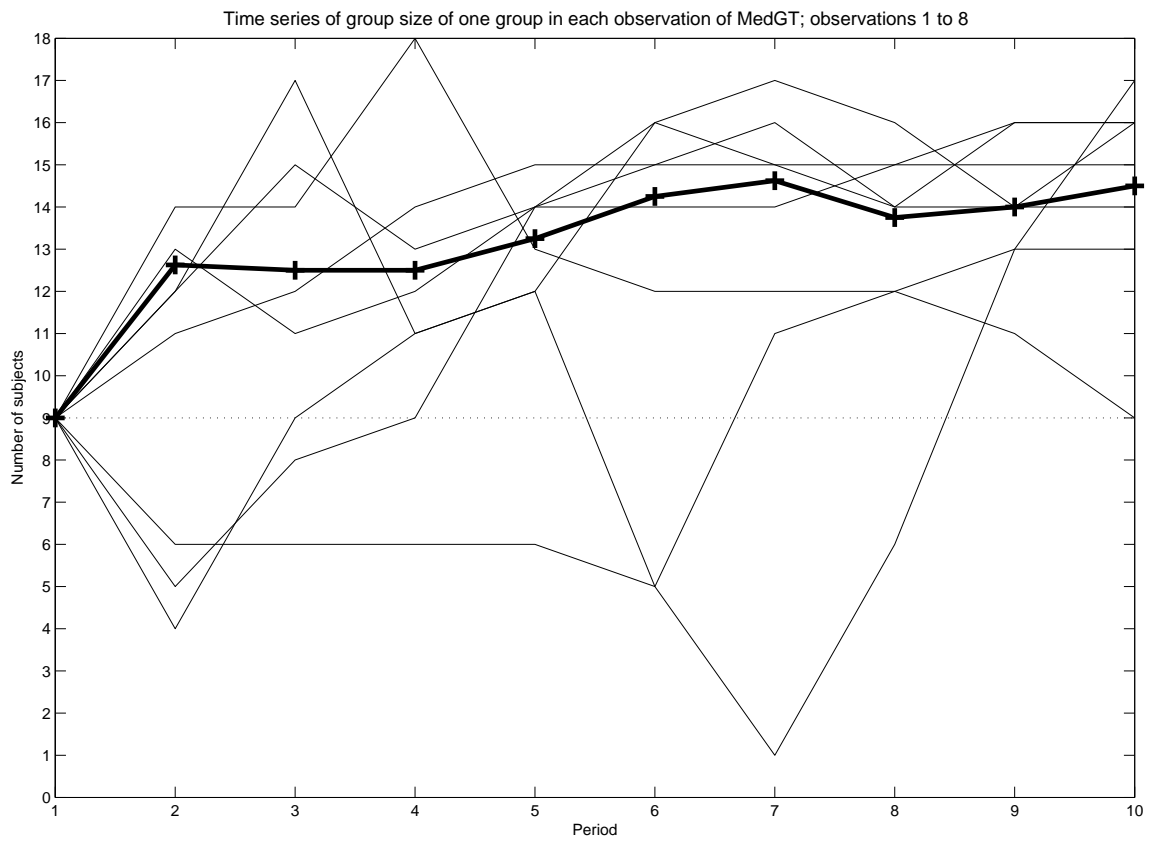

Figure 5: Group sizes in MedGT.

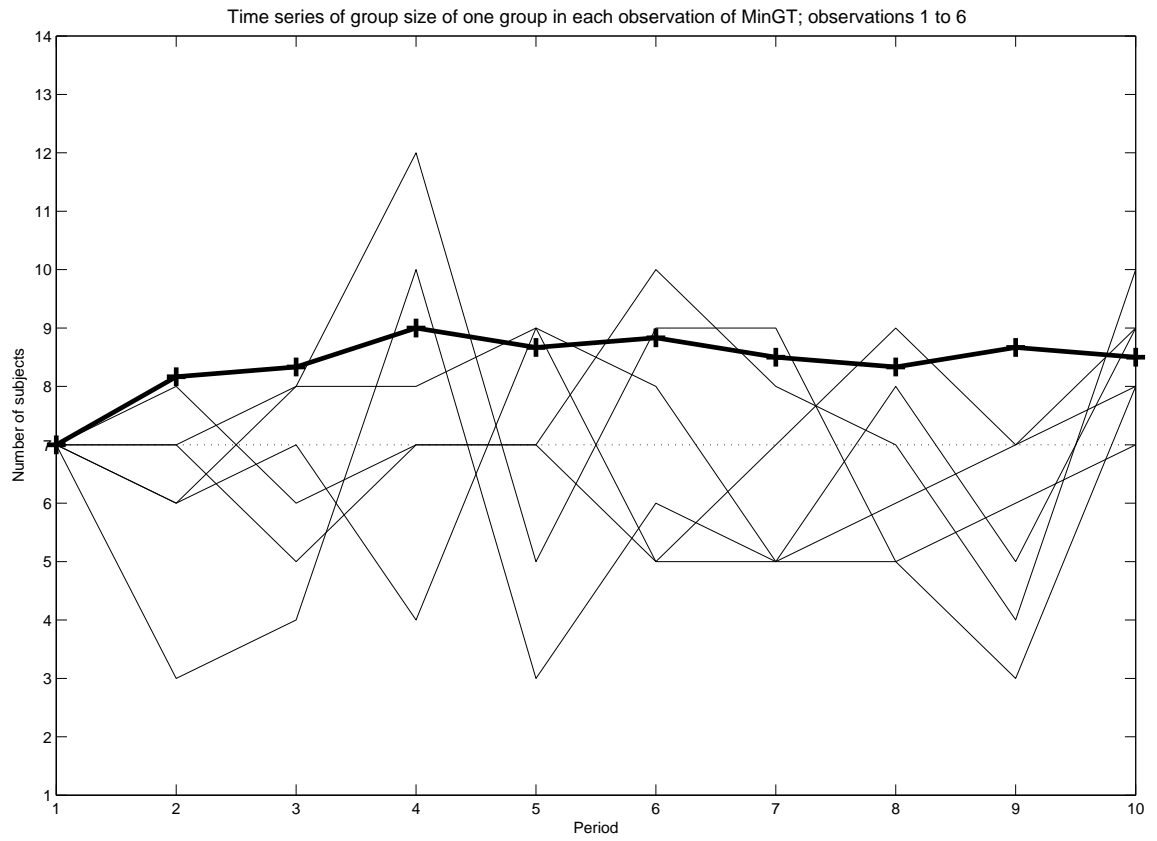

Figure 6: Group sizes in MinGT. 
plotted for each observation in the respective treatment the time series of group size $n_{g}^{t}$ of the group which had the higher number of members in the 10th period. Moreover, for the bold line in figure (5) and (6) we identify, given a certain period, in each observation the higher number of members of the two groups and average these numbers across observations in the respective treatment.

Figure (5) clearly shows that MedGT is favorable to the emergence of large groups. The bold line increases almost steadily up to 14.5 in the last period. This is 1.6 times the equal split of subjects among the two groups. In fact, in the last period only one observation had both groups with 9 subjects each. In the remaining observations the larger group consisted of either $13,14,15,16$, or 17 subjects.

Interestingly, and in contrast to MedGT, the group movements in MinGT had the tendency to equate the group sizes, as can be seen in figure (6). That is the group sizes fluctuated around 7. Moreover, the bold line in MinGT moves close to 8.5 from the fifth period on. 8.5 is only 1.2 times the equal split of subjects among the two groups (i.e. 7 subjects). Remember that the corresponding number for MedGT was 1.6.

Result 5 A considerable amount of group changes are observed both in MedGT and MinGT. Group changes occurred to a larger extent in MinGT than in MedGT. In MinGT almost all group changes occured, even though the minima in the preceding period were the same. In contrast, most of the group changes in MedGT are explained by changes to the group with the higher median in the preceding period. Finally, group changes lead to large/small groups in MedGT and equally sized groups in MinGT.

\subsection{Coordination patterns}

We can distinguish two different patterns of coordination, both for MedGT and MinGT. Figure (7) takes as examples observation 2 and 6 for these patterns in the 8 observations of MedGT. Figure 8 takes observation 2 and 4 of MinGT. The figures display the evolution across periods of the medians (minima) in group $X$ and $Y\left(\operatorname{Med}_{X}, \operatorname{Med}_{Y}\left(\operatorname{Min}_{X}^{t}, \operatorname{Min}_{Y}^{t}\right)\right)$ and the number of subjects in group $X\left(n_{X}^{t}\right)$.

Observation 2 in MedGT displays a similar pattern as observation 4 . In the first period, different medians resulted, both smaller than the maximum median 7 (in observation 2, group $X$ started with a median of 5 , and group $Y$ with a median of 4 ). This in turn caused more and more subjects to switch to group with the higher median (group $X$ ). At some point, when the group with the lower median (group $Y$ ) had become sufficiently small (1 subject), some subjects switched to that group $(Y)$ with higher effort levels. This triggered an increase of the median, achieving in the following periods an higher median for the before smaller and suboptimal group $(Y)$. The "new" difference in medians again initiated the cycle described so far until one group achieved a median of 7 (here group $X$ in period 8). Then either the majority of subjects migrated to the group with the maximum median (observation 2) or after some periods the other group achieved a median of 7 too (observation 4).

Observation 6 in MedGT displays a very similar pattern as observations 1, 3, 5, 7, and 8. In particular, these observations are characterized by the fact that there was always one group which had an higher median than the other group in the respective observation. Moreover, there was an almost constant migration to the higher median group. In observation 6 in figure (7), group $Y$ started already at median 7 in period 1 while group $X$ had a median of 5 . As time 

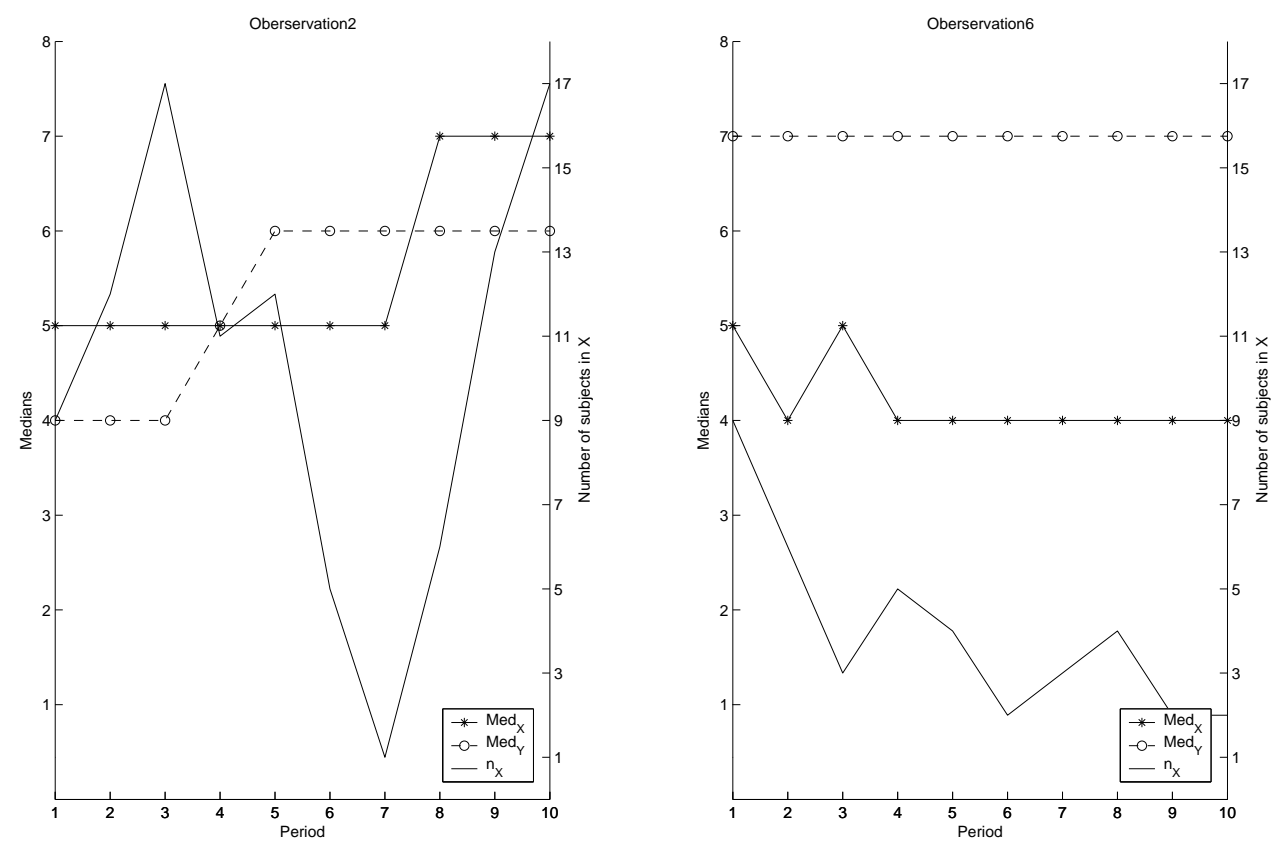

Figure 7: Coordination patterns.
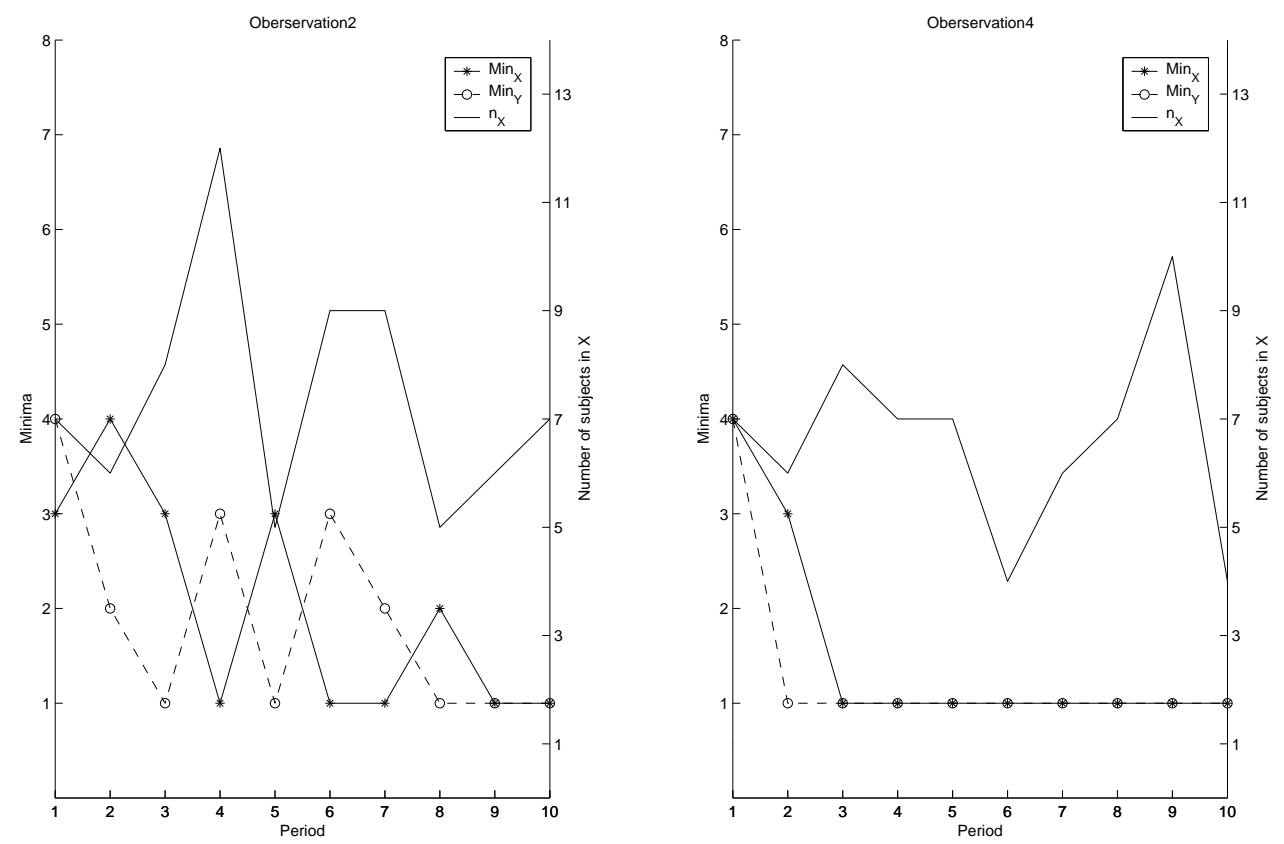

Figure 8: Coordination patterns. 
went by more and more subjects switched to group $Y$. In period 10 only 2 subjects remained in group $X$.

In MinGT Observation 2 displayed a cycling pattern concerning the higher and the lower group minimum per period which was linked to group size in a similar fashion as in observation 3 and 5. This cyclical pattern is characterized by the fact that in most of the periods the majority of subjects chose the group with the higher minimum in the preceding period. However, at least one subject of the now larger group selected an effort such that the minimum in the current period decreased. In contrast, the minimum of the group with the now lower number of subjects in the current period increased in most of the observations. That is, higher and lower minimum group changed. In the following period migration occurred again like above and led to a new switch of the groups having the higher minimum and the lower number of group members. This process continued until in some period both groups reached the same minimum. This was the case at the minimum of 1 in period 9 of observation 2 and in period 7 of observation 3 . In observation 5 both minima settled at 3 from period 8 on. The cycle in observation 3 was somehow weaker. The change of higher and lower minimum group was not from period to period but took about 2 to 3 periods. However, still increasing group size led to a deterioration of the group's minimum.

Observation 4 in MinGT is a typical example for a quick dynamics towards the Paretodominated solution. Observation 1 and 6 displayed a similar decay of group minima. All these observations are characterized by the fact that their first period minima were at least in one group larger than 3 . In the consecutive periods a unique subject in each such group chose an effort smaller than the group's minimum in the preceding period. The decline of minima triggered by such behavior was so fast in these observations that already in the third period at least one group had reached the lowest minimum for the rest of all remaining periods. At latest from the fifth period onwards all three observations had both groups with a minimum of 1 . As mentioned above and as can be seen in figure (8), even though both minima were the same and equal to 1 some group movements were still observed. Moreover these group movements had the property to equalize group sizes among the two groups.

\section{Discussion}

In the theoretical part we proposed a myopic best reply dynamics which leads to the payoffdominant equilibrium under endogenous group formation in both the minimum and median effort game. The model assumes that players always switch to the "better" group, and that deviations from the myopic best reply ("noise") vanish in time. Moreover, given that the groups have the same value of the summary statistics in some period, it postulates that with some positive probability a favorable number of mutations with respect to the group or effort decisions occur. Favorable means, that mutations assure the emergence of very small groups (one player). In fact, such a single player group has no coordination problem anymore. Through endogenous group formation, its presence should therefore warrant the coordination on the payoff-dominant outcome for all players. With respect to group sizes, any distribution of players among the two groups is equally likely to describe the outcome of the process. These predictions hold for both the median and the minimum effort game.

The experimental part teaches us differently. The observed outcomes are completely different in the two types of coordination games under endogenous group formation. In the median effort game considerable Pareto-improvements are observed, and large groups emerge. In the 
minimum effort game the decay of coordination takes the same form as with fixed groups, and groups tend to be equally sized.

Obviously, the proposed myopic best reply dynamics does not account appropriately for the out-of-equilibrium properties and their consequences for behavior in the two games. In particular, the median becomes more and more robust against low-effort deviations the bigger the group is. In contrast, the minimum effort game is sensitive to a unique player's low effort. The additional degree of freedom to select one's group provides players with an instrument to react to the risk of encountering low effort players. This aspect is neglected in the proposed myopic best reply dynamics of section 3. Our experimental results, however, show that it may be crucial for the success of endogenous group formation.

Why is that? Suppose that players hold the following belief: Every other player will play a low-effort with a certain probability (it may be small). Given this and the property of the respective summary statistics, players will look for large groups in the median effort game, but flee them in the minimum effort game. In particular, no player would have an incentive to switch to the other group, once all players are contained in one group in the median effort game. In the minimum effort game, this holds when both groups have the same number of subjects. The respective group structures minimize the probability of facing coordination deteriorating play. In the median effort game this group formation argument is in line with the proposed myopic best reply process. If the medians of the two groups end up at the same level, some small group must form to ensure the upward coordination. Exactly this will be warranted by the risk considerations. In the minimum effort game, however, equally sized groups prevent upward coordination, given that the minima in the two groups are the same. In fact, our experimental results showed that large/small groups formed through group changes in the median effort game, and that pareto-improvements are achieved under endogenous group formation. In the minimum effort game group changes had the tendency to equalize the group sizes. At no point in time a single player group emerged which could have induced upward coordination.

\section{Conclusion}

The answer to the question of the title "Can endogenous group formation prevent coordination failure?" is twofold: Yes and no.

We argued in the theoretical part that endogenous group formation might provide a force which drives coordination towards efficiency. Our experimental part, however, shows that the out-of-equilibrium properties of the coordination game are crucial for the success of the coordination process. In particular, the sensitivity of the respective game to player's deviations determines the coordination result.

Moreover, our experimental results show that the strategic risk of encountering coordination deteriorating players has an influence on how groups form. The different group sizes can be interpreted as minimizing such risk in the respective game. The resulting group sizes from such risk considerations in turn might interfere with the requirements of the coordination process towards efficiency, as play in the minimum effort game shows.

It is up to future research to investigate more thoroughly how group formation driven be risk motives interacts with actual play in the game. 


\section{References}

Berninghaus, S. K., And K.-M. Ehrhart (1998): “Time Horizon and Equilibrium Selection in Tacit Coordination Games: Experimental Results," Journal of Economic Behavior and Organization, 37, 231-248.

(2001): "Coordination and Information: Recent Experimental Evidence," Economic Letters, $73,345-351$.

Blume, A., And A. Ortmann (2000): "The Effects of Costless Pre-Play Communication: Experimental Evidence from a Game With Pareto-Ranked Equilibria," Working Paper.

Bornstein, G., U. Gneezy, and R. Nagel (2002): "The Effect of Intergroup Competition on Group Coordination: An Experimental Study," Games and Economic Behavior, 41, 1-25.

Cachon, G. P., and C. F. Camerer (1996): "Loss-Avoidance and Forward Induction in Experimental Coordination Games," The Quarterly Journal of Economics, 111, 165-194.

Cooper, R., D. V. D. Jong, R. Forsythe, and T. W. Ross (1992): "Forward Induction in Coordination Games," Economics Letters, 40, 167-172.

Devetag, G. (2001): "Precedent Transfer in Coordination Games: Experimental Evidence," Working Paper, University of Trento.

Ehrhart, K.-M., and C. Keser (1999): "Mobility and Cooperation: On the run," Game Theory and Experimental Economics, 3, 1-15.

Ely, J. C. (2002): "Local Conventions," Advances in Theoretical Economics, 2, Article 1.

FischBACheR, U. (1998): "Z-tree- Zürich Toolbox for Readymade Economic Experiments - Eperimenter's Manual," Working Paper Nr. 21, Institute for Empirical Research in Economics, University of Zürich.

Greiner, B. (1998): “An Online Recruting System for Economic Experiments," Discussion Paper 10-2003, Max Planck Institute for Research into Economic Systems, Jena.

Kandori, M., G. J. Mailath, and R. Rob (1993): "Learning, Mutation and Long Run Equilibria in Games," Econometrica, 61, 29-56.

Keser, C., K.-M. Ehrhart, and S. K. Berninghaus (1998): "Coordination and Local Interaction: Experimental Evidence," Economics Letters, 58, 269-275.

Nöldeke, G., And L. Samuelson (1993): "An Evolutionary Analysis of Backward and Forward Induction," Games and Economic Behavior, 5, 425-454.

(1997): “A Dynamic Model of Equilibrium Selection in Signaling Markets," Journal of Economic Theory, 73, 118-156.

Oechssler, J. (1997): "Decentralization and the Coordination Problem," Journal of Economic Behavior and Organization, 32, 119-135.

- (1999): "Competition among Conventions," Computational and Mathematical Organization, 5, 31-44. 
Samuelson, L. (1994): "Stochastic Stability in Games with Alternative Best Replies," Journal of Economic Theory, 64, 35-65.

(1997): Evolutionary Games and Equilibrium Selection. Cambridge, M.A. and London, England: The MIT Press.

Siegel, S., And N. J. Castellan (1988): Nonparametric Statistics for the Behavioral Sciences. McGraw-Hill, New York.

VanHuyck, J. B., R. C. Battalio, and R. O. Beil (1990): "Tacit Coordination Games, Strategic Uncertainty, and Coordination Failure," American Economic Review, 80, 234-248.

(1991): "Strategic Uncertainty, Equilibrium Selection, and Coordination Failure in Average Opinion Games," The Quarterly Journal of Economics, 106, 885-911.

_ (1993): "Asset Markets as an Equilibrium Selection Mechanism: Coordination Failure, Game Form Auctions, and Tacit Communication," Games and Economic Behavior, 5, $485-504$.

VanHuyck, J. B., R. C. Battalio, and F. W. Rankin (2001): "Evidence on Learning in Coordination Games," Working Paper.

Young, P. H. (1993): "The Evolution of Conventions," Econometrica, 61, 57-84. 


\section{A Proof of Proposition 2}

The proof works as follows: The first lemma works out the candidate states for the support of the unique limiting invariant distribution $\varphi^{\diamond}$, namely the absorbing sets of the unperturbed Markov chain $P$. In particular, we show that there exists unique absorbing set, containing all states which constitute a payoff dominant Nash equilibrium. The second lemma shows that there exists a unique invariant distribution for the perturbed dynamics $\varphi(\varepsilon)$. This lemma allows us to use a result by Nöldeke and Samuelson (1993),(1997) to prove our proposition. The result is stated in lemma 3. It postulates that every regularly perturbed finite Markov chain contains at least one set of absorbing sets called a recurrent set that is a minimal set of absorbing sets robust against a single mutation. I.e., given the process is in the recurrent set, any single mutation cannot lead to an absorbing set outside the recurrent set. A necessary condition for a state being contained in the support of the unique limiting invariant distribution is that it is contained in a recurrent set. Since there is only one absorbing set (see lemma 1) it must be the unique recurrent set. This terminates the proof.

Consider $\varepsilon=0$. We first define an absorbing set $A \subseteq E^{N}$ by

(i) $\forall \omega \in A, \forall \omega^{\prime} \notin A, p_{\omega \omega^{\prime}}=0$ and

(ii) $\forall \omega, \omega^{\prime} \in A, \exists k \in \mathbb{N}, k$ finite, s.t. $p_{\omega \omega^{\prime}}^{(k)}>0, p_{\omega \omega^{\prime}}^{(k)}$ being the $k$-step transition probability from $\omega$ to $\omega^{\prime}$.

Lemma 1 The unperturbed dynamics has a unique absorbing set $A^{\diamond}$. This absorbing set consists of all states that are payoff-dominant Nash equilibria.

$$
A^{\diamond}=\left\{\omega^{\diamond} \mid g_{i} \in\{X, Y\} \text { and } e_{i}=\bar{e}, \forall i \in I\right\}
$$

\section{Proof:}

We first show that $A^{\diamond}$ constitutes an absorbing set. We then show that it is unique.

Clearly, given a state $\omega^{\diamond} \in A^{\diamond}$ no player would deviate with respect to his effort decision. Next, all states $\omega^{\diamond} \in A^{\diamond}$ only differ with respect to the group sizes of the two groups. By the indifference assumption 2 there is some positive probability that any partition of players among the two groups can be reached from period $t$ to period $t+1$, given an arbitrary partition of players in period $t$.

For uniqueness we show that the unperturbed dynamics must lead to a state $\omega^{\diamond} \in A^{\diamond}$ starting from an arbitrary state $\omega \in(G \times E)$ different than a state $\omega^{\diamond} \in A^{\diamond}$.

Take such an arbitrary state $\omega \in(G \times E)$. We make the following case distinction:

(i) If the values of the summary statistics in the two groups are the same and all players are indifferent between the two groups, then the indifference assumption 2 warrants that a single player or empty group emerges with positive probability at some point in time. Once such a group has emerged, the following dynamics must lead to a payoff dominant outcome, i.e. to a state $\omega^{\diamond} \in A^{\diamond}$. If a single player group emerges then this player chooses the maximum effort, and all remaining players migrate with maximum effort to that group in the following period. If an empty group emerges then all players switch to the empty group with the maximum effort in the consecutive period.

(ii) Next, assume that the values of the summary statistics are the same (if both values exist), but that at least one player is not indifferent between the two groups ${ }^{13}$. This can only be

\footnotetext{
${ }^{13}$ Of course, if there is an empty group there is only one value of the summary statistics.
} 
because there is a single player or empty group in that state $\omega$. Then, for the same reasons than above, the unperturbed dynamics will lead to a state $\omega^{\diamond} \in A^{\diamond}$.

(iii) Assume that the values of the two summary statistics are unequal in state $\omega$ of period $t$ (if both values exist). As long as there is no single player or empty group all players will switch to the group with the higher summary statistics in period $t+1$, such that one empty group remains. But then all players switch back to the latter group in period $t+2$ with the maximum effort. If there is a single player or empty group, then, for the same reasons as above, the dynamics will lead to the payoff dominant outcome. In any case we end up in a state $\omega^{\diamond} \in A^{\diamond}$.

Lemma 2 Suppose that the conditions of proposition 1 hold. If $\varepsilon \in(0, a]$ then $P(\varepsilon)$ is regularly perturbed.

In order to show that $P(\varepsilon)$ is regularly perturbed we have to show that the three following properties are fulfilled:

(i) $P(\varepsilon)$ is ergodic,

(ii) $\lim _{\varepsilon \rightarrow 0} P(\varepsilon)=P$, and

(iii) if $p_{\omega \omega^{\prime}}(\varepsilon)>0$ for some $\varepsilon \in(0, a] \Rightarrow \exists r \geq 0$ s.t. $0<\lim _{\varepsilon \rightarrow 0}(\varepsilon)^{-r} p_{\omega \omega^{\prime}}(\varepsilon)<\infty$.

Note that ergodicity implies that there exists a unique invariant distribution $\varphi(\varepsilon)$ for $P(\varepsilon)$.

\section{Proof:}

(i) A sufficient condition for ergodicity is that $P(\varepsilon)$ is strictly positive. Since $\varepsilon>0$, this trivially holds.

(ii) By continuity of $P, \lim _{\varepsilon \rightarrow 0} P(\varepsilon)=P$ follows.

(iii) Proof by contradiction: Assume that $\forall r \geq 0$ we have either (a) $\lim _{\varepsilon \rightarrow 0}(\varepsilon)^{-r} p_{\omega \omega^{\prime}}(\varepsilon)=0$ or (b) $\lim _{\varepsilon \rightarrow 0}(\varepsilon)^{-r} p_{\omega \omega^{\prime}}(\varepsilon)=\infty$. Since $\varepsilon$ is strictly positive case (a) can only be satisfied if $p_{\omega \omega^{\prime}}(\varepsilon)=0$, a contradiction. Since $p_{\omega \omega^{\prime}}(\varepsilon) \leq 1$ case (b) only holds if $(\varepsilon)^{r}$ becomes very small. In that case we can reduce $r$ such that $p_{\omega \omega^{\prime}}(\varepsilon)$ becomes of order $(\varepsilon)^{r}$, a contradiction.

The following lemma of Nöldeke and Samuelson (1993),(1997) terminates the proof of the proposition, as outlined before.

Lemma 3 (Nöldeke/Samuelson) Given a regularly perturbed finite

Markov chain, then at least one recurrent set exists. Recurrent sets are disjoint. Let the state $\omega$ be contained in the support of the unique limiting invariant distribution $\varphi^{\diamond}$. Then $\omega \in R$, $R$ being a recurrent set. Moreover, $\forall \omega^{\prime} \in R, \varphi^{\diamond}\left(\omega^{\prime}\right)>0$.

(For a proof of lemma 3 see Samuelson (1997) lemma 7.1 and proposition 7.7., proof pp. 236 - 238. See also Nöldeke/Samuelson(1993, 1997) and Samuelson (1994).)

\section{B Instructions}

Translation of the instructions in the MedGT (MinGT):

\section{Welcome to the experiment!}


In this experiment you can earn money by making decisions. Your earnings will depend on your decisions as well as the decisions of the other participants. Please do not talk to other participants from now on.

There are 18 (MinGT: 14) participants in the experiment (except you 17 (MinGT: 13) others). Each participant receives the same instructions and information.

\section{The course of the experiment is as follows:}

In the first period the participants will be randomly distributed among two groups $X$ and $Y$. You will see on the computer screen to which of the two groups you belong. In both groups $X$ and $Y$ there will be an equal number of participants (that is 9 (MinGT: 7 ) in each group). Afterwards you choose a number from 1, 2, 3, 4, 5, 6, 7 .

In periods 2 to 10 you make two decisions:

- Group decision: You can choose in the beginning of each period in which of the two groups $X$ and $Y$ you want to be in the actual period.

- Number decision: Furthermore you have to choose a number from 1, 2, 3, 4, 5, 6, 7 in each period.

The number decisions of the members of your group determine your period payoff as follows:

\section{MedGT}

\section{Period payoff:}

Your period payoff is determined by your chosen number and the median (see explanation below) of all numbers which have been chosen in your group. That is, number decisions of members of the other group do not have any influence on your period payoff.

What is the median? For a list of numbers the median is the number for which half of the remaining numbers are lower or equal to that number, and the other half is greater or equal to that number!

If there is an odd number of numbers in the list there is an easy way to determine the median. Take e.g. the list of the following five numbers: 45, 53, 51, 47, 47. First you sort the numbers with respect to their magnitude; $45,47,47,51,53$. Then you cross out pairwise the smallest and the largest number until only one number remains. The remaining number is median: 45 , $47,47,51,53$. Here 47 is the median.

If there is an even number of numbers in the list you proceed like above except that you stop crossing out the smallest and largest numbers already when there are only two numbers left. The computer will then determine one of the two numbers randomly. Both numbers are equally likely. Take e.g. the list of the following four numbers: 47, 47, 51, 53 (already sorted and crossed out). With equal probability either 47 or 51 will be determined as median.

A payoff table is attached to these instructions. It shows you how your period payoff results depending on your number chosen and the median in your group.

In the table the period payoffs are displayed in tokens. To the very left in the first column your possible choice of a number is displayed. In the first row the possible medians are displayed. 
Thus you can look up for every median which period payoff would result for your chosen number.

\section{Example:}

Suppose you have chosen to be in group $Y$. Moreover you believe that 6 other participants have chosen group $Y$ too. Suppose you choose the number 4 . If you believe that from the 7 numbers in your group a median of 3 results, then you can easily look up your period payoff in the table. For this you go down in the column of the group median equal to 3 to the row where your chosen number of 4 is displayed. Thus your period payoff in this example would be 170 .

\section{Your payoff in Euro:}

The sum of all 10 period payoffs plus an initial endowment of 500 tokens is your total payoff in the experiment. This sum will be converted into Euros as follows: 100 tokens $=0.27$ Euros.

\section{MinGT}

\section{Period payoff:}

Your period payoff is determined by your chosen number and the smallest number of all participants in your group - including your own number. That is, number decisions of members of the other group do not have any influence on your period payoff.

A payoff table is attached to these instructions. It shows you how your period payoff results. The period payoffs are given in tokens in the table. To the very left in the first column your possible choice of a number is displayed. In the first row the smallest number in your respective group is displayed. If you go down in one of the columns of the smallest number in your group up to the row of your number choice you can read your period payoff.

Remark: In the table there are cells with an "-" as entry. This shows you that the respective combination of own chosen number and the smallest number in your group is not possible. If you e.g. chose the number 4 the smallest number in your group cannot be 7, 6, or 5 .

Example: Suppose e.g. that in one period you have chosen group $X$. Moreover you believe that 6 other participants haven chosen group $X$. Suppose you choose the number 5 . If you believe that the smallest number of your number and the 6 numbers of the participants in group $X$ is 4 , you can easily check up your period payoff. For this you go down in the column of the smallest number of 4 to the row where your number choice of 5 is displayed. Thus your period payoff in this example would be 90 .

\section{Your payoff in Euro:}

The sum of all 10 period payoffs is your total payoff in tokens in the experiment. This sum will be converted into Euros as follows: 100 tokens $=0.006$ Euros. Thus 10 tokens are 0.06 Euros.

\section{Input window and information during the experiment:}

This screenshot shows you the input window as it will appear to you after the first period. Under (1) Values of the preceding period you find for all preceding periods the following 
values: 1. Your group decision. 2. Your chosen number ("Your number"). 3. The number of players in the two groups $X$ and $Y$ ("Amount in $X(Y)$ ). 4. The medians in group $X$ and $Y$ (MinGT: The smallest number in group $X(Y)$ ("Smallest number in $X(Y)$ "). 5. Your period payoff in tokens ("Payoff"), and 6. the sum of all period payoffs up to the actual period in tokens ("Total payoff"). Please enter your group decision in field (2) and in field (3) your chosen number. In field (4) Confirmation of your choice you approve your group and number decision by clicking "OK". After "clicking" the "OK" button a window appears which summarizes the respective period result.

Remark: If in any period all 18 ( MinGT: 14) participants choose the same group such that there is no participant in one group then 0 will be displayed as median (MinGT: smallest number) for the latter group.

\section{Further procedure:}

Please read again carefully over the instructions, and study the payoff table. If there are no questions anymore concerning the instructions we will inform you about the further procedure in the experiment.

\section{Payoff Tables}

\begin{tabular}{|c|c|c|c|c|c|c|c|c|}
\hline & \multicolumn{7}{|c|}{ Median } \\
\hline & & 7 & 6 & 5 & 4 & 3 & 2 & 1 \\
\hline & 7 & 260 & 230 & 180 & 110 & 20 & -90 & -220 \\
\hline & 6 & 250 & 240 & 210 & 160 & 90 & 0 & -110 \\
\hline & 5 & 220 & 230 & 220 & 190 & 140 & 70 & -20 \\
\hline Effort & 4 & 170 & 200 & 210 & 200 & 170 & 120 & 50 \\
\hline & 3 & 100 & 150 & 180 & 190 & 180 & 150 & 100 \\
\hline & 2 & 10 & 80 & 130 & 160 & 170 & 160 & 130 \\
\hline & 1 & -100 & -10 & 60 & 110 & 140 & 150 & 140 \\
\hline
\end{tabular}

Figure 9: - Payoff table in MedGT and MedCT.

\begin{tabular}{|c|c|c|c|c|c|c|c|c|}
\hline & & \multicolumn{7}{|c|}{ Minimum } \\
\hline & & 7 & 6 & 5 & 4 & 3 & 2 & 1 \\
\hline \multirow{7}{*}{ Effort } & 7 & 130 & 110 & 90 & 70 & 50 & 30 & 10 \\
\hline & 6 & - & 120 & 100 & 80 & 60 & 40 & 20 \\
\hline & 5 & - & - & 110 & 90 & 70 & 50 & 30 \\
\hline & 4 & - & - & - & 100 & 80 & 60 & 40 \\
\hline & 3 & - & - & - & - & 90 & 70 & 50 \\
\hline & 2 & - & - & - & - & - & 80 & 60 \\
\hline & 1 & - & - & - & - & - & - & 70 \\
\hline
\end{tabular}

Figure 10: - Payoff table in MinGT. 